\title{
Technical Note: Validation of Odin/SMR limb observations of ozone, comparisons with OSIRIS, POAM III, ground-based and balloon-borne instruments
}

\author{
F. Jégou ${ }^{1}$, J. Urban ${ }^{2}$, J. de La Noë ${ }^{3}$, P. Ricaud ${ }^{4}$, E. Le Flochmoën ${ }^{4}$, D. P. Murtagh ${ }^{2}$, P. Eriksson ${ }^{2}$, A. Jones ${ }^{2}$, \\ S. Petelina ${ }^{5,14}$, E. J. Llewellyn ${ }^{5}$, N. D. Lloyd ${ }^{5}$, C. Haley ${ }^{6}$, J. Lumpe ${ }^{7}$, C. Randall ${ }^{8}$, R. M. Bevilacqua ${ }^{9}$, V. Catoire ${ }^{10}$, \\ N. Huret ${ }^{10}$, G. Berthet ${ }^{10}$, J. B. Renard ${ }^{10}$, K. Strong ${ }^{11}$, J. Davies ${ }^{12}$, C. T. Mc Elroy ${ }^{12}$, F. Goutail ${ }^{13}$, and \\ J. P. Pommereau ${ }^{13}$ \\ ${ }^{1}$ Laboratoire des Sciences du Climat et de l'Environnement, Gif sur Yvette, France \\ ${ }^{2}$ Chalmers University of Technology, Göteborg, Sweden \\ ${ }^{3}$ Université Bordeaux 1, CNRS/INSU, Laboratoire d'Astrophysique de Bordeaux, Floirac, France \\ ${ }^{4}$ Laboratoire d'Aérologie, Toulouse, France \\ ${ }^{5}$ University of Saskatchewan, Saskatoon, Canada \\ ${ }^{6}$ York University, Toronto, Canada \\ ${ }^{7}$ Computational Physics, Inc., Boulder, Colorado, USA \\ ${ }^{8}$ Laboratory for Atmospheric and Space Physics, Univ. of Colorado, Boulder, Colorado, USA \\ ${ }^{9}$ Naval Research Laboratory, Washington, D.C., USA \\ ${ }^{10}$ Laboratoire de Physique et de Chimie de l'Environnement, Orléans, France \\ ${ }^{11}$ Department of Physics, University of Toronto, Toronto, Canada \\ ${ }^{12}$ Environment Canada, Toronto, Canada \\ ${ }^{13}$ Service d'Aéronomie, Paris, France \\ ${ }^{14}$ La Trobe University, Victoria, Australia
}

Received: 23 October 2007 - Published in Atmos. Chem. Phys. Discuss.: 11 January 2008

Revised: 27 May 2008 - Accepted: 2 June 2008 - Published: 30 June 2008

\begin{abstract}
The Odin satellite carries two instruments capable of determining stratospheric ozone profiles by limb sounding: the Sub-Millimetre Radiometer (SMR) and the UVvisible spectrograph of the OSIRIS (Optical Spectrograph and InfraRed Imager System) instrument. A large number of ozone profiles measurements were performed during six years from November 2001 to present. This ozone dataset is here used to make quantitative comparisons with satellite measurements in order to assess the quality of the Odin/SMR ozone measurements. In a first step, we compare Swedish SMR retrievals version 2.1, French SMR ozone retrievals version 222 (both from the $501.8 \mathrm{GHz}$ band), and the OSIRIS retrievals version 3.0, with the operational version 4.0 ozone product from POAM III (Polar Ozone Atmospheric Measurement). In a second step, we refine the Odin/SMR validation
\end{abstract}

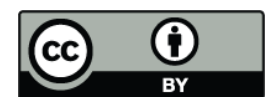

Correspondence to: F. Jégou (fjegou@cea.fr) by comparisons with ground-based instruments and balloonborne observations. We use observations carried out within the framework of the Network for Detection of Atmospheric Composition Change (NDACC) and balloon flight missions conducted by the Canadian Space Agency (CSA), the Laboratoire de Physique et de Chimie de 1'Environnement (LPCE, Orléans, France), and the Service d'Aéronomie (SA, Paris, France). Coincidence criteria were $5^{\circ}$ in latitude $\times 10^{\circ}$ in longitude, and $5 \mathrm{~h}$ in time in Odin/POAM III comparisons, $12 \mathrm{~h}$ in Odin/NDACC comparisons, and $72 \mathrm{~h}$ in Odin/balloons comparisons. An agreement is found with the POAM III experiment (10-60 km) within $-0.3 \pm 0.2 \mathrm{ppmv}$ (bias \pm standard deviation) for SMR (v222, v2.1) and within $-0.5 \pm 0.2 \mathrm{ppmv}$ for OSIRIS (v3.0). Odin ozone mixing ratio products are systematically slightly lower than the POAM III data and show an ozone maximum lower by $1-5 \mathrm{~km}$ in altitude. The comparisons with the NDACC data (10-34 km for ozonesonde, $10-50 \mathrm{~km}$ for lidar, $10-60$ for microwave instruments) yield a good agreement within $-0.15 \pm 0.3$ ppmv for the SMR data

Published by Copernicus Publications on behalf of the European Geosciences Union. 
and $-0.3 \pm 0.3$ ppmv for the OSIRIS data. Finally the comparisons with instruments on large balloons (10-31 km) show a good agreement, within $-0.7 \pm 1 \mathrm{ppmv}$. The official SMR v2.1 dataset is consistent in all altitude ranges with POAM III, NDACC and large balloon-borne instruments measurements. In the SMR v2.1 data, no different systematic error has been found in the $0-35 \mathrm{~km}$ range in comparison with the $35-60 \mathrm{~km}$ range. The same feature has been highlighted in both hemispheres in SMR v2.1/POAM III intercomparisons, and no latitudinal dependence has been revealed in SMR v2.1/NDACC intercomparisons.

\section{Introduction}

Satellite sensors play a crucial role in monitoring the chemical and dynamic structure of the atmosphere thanks to their global spatial and temporal coverage. New space missions are continually necessary to provide information for understanding ozone and climate change.

The atmospheric composition can be measured from space by several techniques that include nadir observations of scattered sunlight, occultation of direct solar and stellar light, and limb measurements of the scattered and thermally emitted radiation. Nadir observations are characterized by excellent geographic coverage but a coarse height resolution, while occultation techniques have good height resolution but in general poor geographic coverage, especially the solar occultation technique. The limb-scattering and limb-emission techniques have the advantage of both high vertical resolution and good geographic coverage but with limited horizontal resolution. The Odin satellite was launched in February 2001 to measure limb-scattered solar radiances and limb thermal emission with the main goal of deriving vertical profiles of minor species in the stratosphere (Murtagh et al., 2002).

Forward models for the sub-mm wavelength range and inversion codes using the Optimal Estimation Method (OEM) permit the retrieval of vertical profiles in the stratosphere and mesosphere. Two codes were developed in parallel, one at the Université Bordeaux 1, Observatoire de Bordeaux, named MOLIERE (Urban et al., 2004a), a second one at the Chalmers University of Technology, Göteborg, Sweden, named ARTS/Qpack (Buehler et al., 2005; Eriksson, 2006). A code based on the technique described by Flittner et al. (2000) and McPeters et al. (2000) was developed to analyse the OSIRIS data and provide vertical profiles of ozone.

It is necessary to assess the quality of the data from the Odin SMR and OSIRIS sensors by well-tested and proven instruments. The assessment also helps to improve the calibration, refine inversion algorithms and detect possible errors. Validation of space-borne sensors is usually carried out with a large amount of correlative data, including high vertical resolution balloon-borne and ground-based measurements with known accuracy, which ideally cover all seasons to obtain good statistics from the comparisons. Furthermore, a criterion should be selected for the comparisons so that the temporal resolution should address the natural variability and the spatial resolution should resolve relevant gradients in the measurements.

The comparisons presented in this study address the quality of the SMR stratospheric ozone profiles for the 4-year period from November 2001 to July 2005. This period is long enough to find seasonal dependencies in the retrievals. The SMR ozone profiles are compared on a monthly basis with data retrieved from the space-borne instruments OSIRIS and POAM III and with ground-based instruments of the Network for Detection of Atmospheric Composition Change (NDACC). This paper is structured in the following manner: (2) a brief description of the Odin mission, (3) statistical monthly intercomparisons of zonally-averaged coincident SMR, OSIRIS and POAM III stratospheric ozone profiles, (4) an evaluation of Odin SMR/OSIRIS ozone measurements against results obtained from well-established and validated ground-based instruments and remote sensors operated onboard stratospheric balloons, providing accurate measurements but with a rather limited coverage in space and time, (5) discussion of the results and concluding remarks.

\section{Odin satellite measurements}

Odin is a Swedish-led scientific mission that also includes France, Canada, and Finland (Murtagh et al., 2002; Llewellyn et al., 2003). Odin was launched on 20 February 2001 into a polar, sun-synchronous, near-terminator orbit. The maximal latitudinal coverage in the orbit plane ranges from $82.5^{\circ} \mathrm{N}$ to $82.5^{\circ} \mathrm{S}$. The goal of the Odin aeronomy mission is to produce vertical profiles of atmospheric constituents such as $\mathrm{O}_{3}, \mathrm{~N}_{2} \mathrm{O}, \mathrm{OClO}, \mathrm{ClO}, \mathrm{BrO}$, $\mathrm{CO}, \mathrm{HNO}_{3}, \mathrm{H}_{2} \mathrm{O}, \mathrm{NO}_{2}, \mathrm{NO}, \mathrm{HO}_{2}$, isotopes of $\mathrm{H}_{2} \mathrm{O}$ and $\mathrm{O}_{3}$ and aerosols. Nearly $67 \%$ of the Odin aeronomy observational time is spent scanning between $7 \mathrm{~km}$ and $70 \mathrm{~km}$ (stratospheric mode), while the majority of the rest is spent scanning from 7 to $110 \mathrm{~km}$ (strato-meso mode).

Odin has two optically co-aligned instruments: the SubMillimetre Radiometer (SMR) and the Optical Spectrograph and InfraRed Imager System (OSIRIS). Key elements of SMR are a $1.1 \mathrm{~m}$ telescope and four tunable single-sideband Schottky-diode heterodyne receivers that passively measure the limb thermal emission in the spectral range of 486$581 \mathrm{GHz}$, as well as two high-resolution auto-correlator spectrometers (Frisk et al., 2003; Olberg et al., 2003). Usually measurements are performed in stratospheric mode twice a week, and atmospheric constituents such as $\mathrm{O}_{3}, \mathrm{ClO}$, $\mathrm{N}_{2} \mathrm{O}$, and $\mathrm{HNO}_{3}$ are retrieved from limb observations in two frequency bands centred at $501.8 \mathrm{GHz}$ and $544.6 \mathrm{GHz}$ (Urban et al., 2004b, 2005). 
In this paper, we assess the quality of the main Odin/SMR level 2 ozone products from the $501.8 \mathrm{GHz}$ band, obtained by the two most recent algorithm versions: Version 2.1 (or "Chalmers-v2.1") is the official product of the Chalmers University of Technology, Göteborg, Sweden; Version 222 of the so-called Chaîne de Traitement Scientifique Odin (CTSO) is the reference product initially developed at the Observatoire Aquitain des Sciences de l'Univers, Bordeaux, France and since 2005 at the Laboratoire d'Aérologie, Toulouse, France. This alternative version ("CTSO-v222") serves to evaluate the quality of the operational SMR products.

The OSIRIS spectrograph measures scattered sunlight over the wavelength range $280 \mathrm{~nm}$ to $800 \mathrm{~nm}$. The vertical sampling is about $1 \mathrm{~km}$ in height at the tangent point. OSIRIS is capable of measuring vertical profiles of stratospheric $\mathrm{O}_{3}$, $\mathrm{NO}_{2}$ and aerosols. Ozone number density profiles are retrieved from the OSIRIS limb radiance spectra in the Chappuis absorption band between 10 and $46 \mathrm{~km}$ on a $2-\mathrm{km}$ grid using the inversion technique originally developed by Flittner et al. (2000) for the SOLSE/LORE experiment and adapted to OSIRIS by Von Savigny et al. (2003). In this paper we use version 3.0 of the OSIRIS data. The vertical resolution of the OSIRIS measurements varies from about $1 \mathrm{~km}$ at $7 \mathrm{~km}$ to $2.5 \mathrm{~km}$ at $70 \mathrm{~km}$. The total error for the OSIRIS ozone retrievals is estimated to be $6 \%$ at about $24 \mathrm{~km}$, increasing roughly linearly to $12-14 \%$ at $10 \mathrm{~km}$ and $33 \%$ at $44 \mathrm{~km}$ (Haley et al., 2007).

For the stratospheric mode, SMR vertical sampling corresponds to about $\sim 1.5 \mathrm{~km}$ (below $50 \mathrm{~km}$ ) in the stratosphere and $\sim 6 \mathrm{~km}$ in the mesosphere. The SMR vertical resolution is about $3 \mathrm{~km}$ in the middle stratosphere. Odin scans have a spatial horizontal resolution along the satellite track of $\sim 500 \mathrm{~km}$. The SMR single-scan precision due to measurement noise is of the order of $0.25-1.5 \mathrm{ppmv}(20-25 \%)$ and the estimated total systematic error is less than $0.4 \mathrm{ppmv}$ at $25-50 \mathrm{~km}$, and less than $0.75 \mathrm{ppmv}$ below $25 \mathrm{~km}$ (Urban et al., 2005).

The following text summarises four recent studies concerning the validation of the SMR ozone data. (1) The improvement of the Chalmers retrieval algorithm has been recently evaluated by Jones et al. (2007). Three versions (v1.2, v2.0 and v2.1) of Odin/SMR ozone have been compared with MIPAS v4.61 and balloon sonde data during 2003. The v2.1 showed the smallest systematic differences compared to both coincident MIPAS and sonde data, especially below $25 \mathrm{~km}$. In this lower stratospheric region, v2.1 was only slightly smaller than MIPAS by less than 0.25 ppmv, while comparisons to sonde measurements showed an agreement within \pm 0.3 ppmv. The largest systematic differences for this version were seen in the tropics, where a negative bias of $0.7 \mathrm{ppmv}$ between $25-37 \mathrm{~km}$ was found. (2) The v222 data have been compared to the ASUR (Airbone Submillimeter Radiometer) instrument deployed onboard the Falcon research aircraft during the SCIAVALUE (September 2002, February/March 2003) and EUPLEx (Jan-
uary/February 2003) campaigns (Kuttippurath et al., 2007). A very good agreement is found in the tropics at $25-34 \mathrm{~km}$, where the difference are within 5\%. Above $35 \mathrm{~km}$ the deviation is slightly higher, up to $40 \%$. The deviation in the high and mid-latitudes is within $\pm 15 \%$ between 20 and $40 \mathrm{~km}$. (3) An intercomparison of $\mathrm{O}_{3}$, profiles measured by SMR and MLS (Microwave Limb Sounder) on board Aura satellite has been performed by Barret et al., 2006. SMR (v222) and MLS (v1.5) have been compared over a few days in September 2004 and March 2005. SMR is found significantly biased high relative to MLS in the lower stratosphere at and below the ozone peak. Relative biases vary from $9 \%$ in the tropics to $18 \%$ at high latitudes. An average bias of 5 to $9 \%$ is found between $31(\sim 25 \mathrm{~km})$ and $10 \mathrm{hPa}(\sim 32 \mathrm{~km})$ in all latitudes and both seasons. (4) A study of the consistency between stratospheric ozone products from the two independent instruments (SMR and OSIRIS) onboard the Odin satellite, was carried out by Brohede et al. (2007). This is relevant for validating the data products, but it is also interesting because the instruments represent fundamentally different measurement techniques: limb emission sounding at submillimetre wavelengths versus UV-visible limb-scatter technique. Since OSIRIS and SMR are mounted on the same platform and are co-aligned, they give perfect matches in time and space. Comparisons are made between OSIRIS version 3.0 and SMR version 2.1 ozone data in order to evaluate the consistency of the Odin ozone data sets. Results show a good agreement between OSIRIS and SMR in the range 25$40 \mathrm{~km}$, where systematic differences are less than $15 \%$ for all latitudes and seasons. Larger systematic differences are seen below $25 \mathrm{~km}$, which can be explained by the increase of various error sources and lower signals. The random differences are between $20-30 \%$ in the middle stratosphere. There is little variation from year to year, but a slight positive trend in the differences (OSIRIS minus SMR) of $0.045 \mathrm{ppmv} / \mathrm{year}$ at $30 \mathrm{~km}$ over validation period (2002-2006). The fact that the two fundamentally different measurement techniques agree so well, provides confidence in the robustnes of both techniques.

\section{POAM III measurements}

\subsection{POAM III mission}

The Polar Ozone and Aerosol Measurement (POAM) III instrument was developed by the Naval Research Laboratory (NRL) to measure the vertical distribution of atmospheric ozone, water vapour, nitrogen dioxide, aerosol extinction, and temperature. Under cloud-free conditions POAM III routinely measures well down in the troposphere. POAM III measures solar extinction in nine narrow band channels, covering the spectral range from 354 to $1018 \mathrm{~nm}$. Solar extinction by the atmosphere is measured using the solar occultation technique; the Sun is observed through the Earth's 


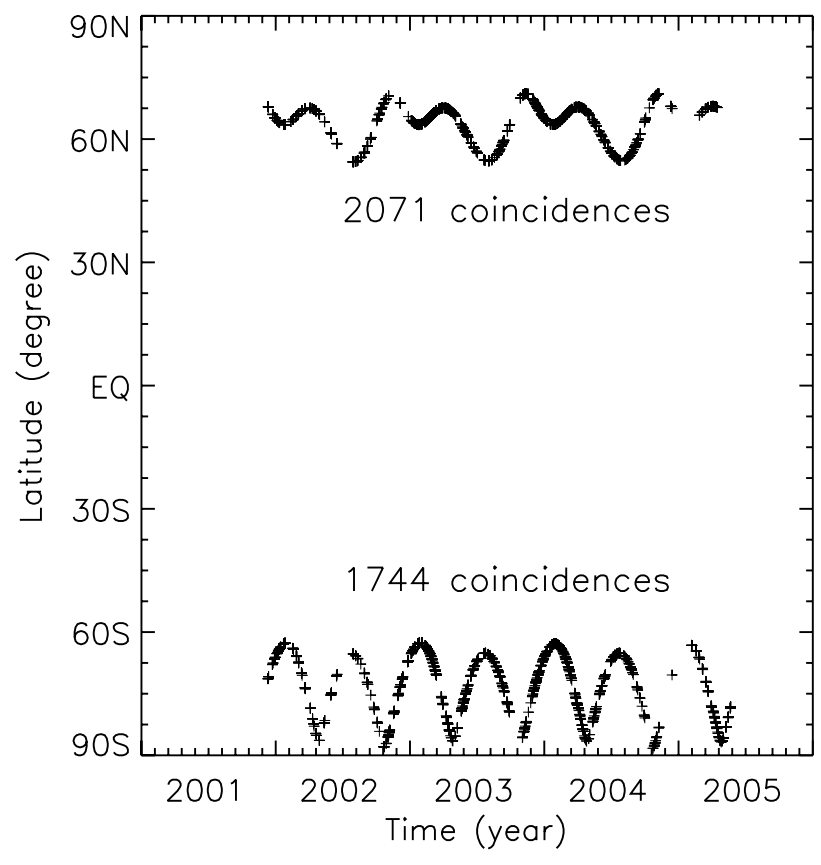

Fig. 1. Latitudes of the POAM III - Odin coincident measurements in the Northern Hemisphere (2071 coincidences) and in the Southern Hemisphere (1744 coincidences) from November 2001 to July 2005.

atmosphere as it rises and sets, as viewed from the satellite. POAM III was launched aboard the French SPOT-4 satellite in March 1998 into a sun-synchronous polar orbit. As seen from the satellite, the Sun rises in the Northern polar region and sets in the Southern polar region 14.2 times per day. Sunrise measurements are made in a latitude band $55-71^{\circ}$ North while sunsets occur between 63 and $88^{\circ}$ South. The longitude ranges from $0^{\circ}$ to $360^{\circ}$. Successive occultations occur around a circle of nearly constant latitude (cf. Fig. 1), and separated by $\sim 25.4^{\circ}$ in longitude. The vertical resolution of the POAM III ozone profiles is $1 \mathrm{~km}$ from 15 to $50 \mathrm{~km}, 1.5 \mathrm{~km}$ at $10 \mathrm{~km}$, more than $5 \mathrm{~km}$ at $5 \mathrm{~km}$, and reaching $2.5 \mathrm{~km}$ by $60 \mathrm{~km}$. The predicted instrumental random error is about $5 \%$ or less in the range $12-50 \mathrm{~km}$ and increases rapidly below $12 \mathrm{~km}$ until $20 \%$, largely due to signal noise. In addition to the random error, error bars include components due to aerosol extinction interference and sunspot artefacts. Sunspots affect the ozone retrievals primarily in the altitude range from 25 to $40 \mathrm{~km}$, but even in this altitude range $\leq 10 \%$ of the ozone data are predicted to suffer from the sunspot artefacts that results in random errors of more than about $10 \%$ (Lumpe et al., 2002). Further details about the POAM III instrument can be found in Lucke et al. (1999). The POAM III v3.0 ozone validation has been performed by Randall et al. (2003). In this paper the POAM III-HALOE and POAM III-SAGE II comparisons concluded to an excellent quality of the POAM III data from 13 to $60 \mathrm{~km}$, with an accuracy of $5 \%$ and suggest a very small $(\leq 5 \%)$ sunrise/sunset bias in the POAM III data from 30 to $60 \mathrm{~km}(\mathrm{sr} \leq \mathrm{ss})$. These results are consistent with the results of Lumpe et al. (2002), who compared measurements from seven different instruments in the SOLVE campaign and found an agreement within 7-10\%. In our intercomparsions we use the POAM III v4.0 ozone data. Informations about this last POAM III algorithm can be found in Lumpe et al. (2006).

\subsection{Comparisons with POAM III satellite observations}

A statistical analysis of comparisons between Odin retrievals from SMR (version 2.1, version 222) and OSIRIS (version 3.0) and POAM III (version 4.0) measurements has been performed. For statistical analyses with correlative satellite data, coincidence criteria were $5^{\circ}$ in latitude $\mathrm{x} 10^{\circ}$ in longitude and $5 \mathrm{~h}$ in time. We have not applied a vortex location criterion because the statistical results for the large number of coincidences studied here are insensitive to this criterion. Average profiles are created by selecting all the measurements satisfying the coincidence criteria. A preliminary selection for each instrument based on the quality flag has been done to eliminate questionable data due to bad radiance fits. This flag contains status information for various error, warning or informative purposes. For Odin data these errors are divided into different groups: moon in or near field of view, selfcontained in or near the South Atlantic anomaly, potential temperature problem ( $\geq 2 \mathrm{~km}$ offset) and optical bench temperature $\leq 15^{\circ} \mathrm{C}$ (potential point spread function problems). Only measurements with quality flag assigned to zero (no error detected) have been selected. To refine this first selection, only good quality measurements have been retained with measurement response larger than 0.75 to ensure a minor contribution of the climatological a priori profile in the retrieved value. When the measurement response is zero, all the information comes from the a priori profile, needed in the OEM retrieval. The higher the measurement response is, the larger is the contribution of the measurement to the retrieved values.

In general SMR profiles show measurement responses larger than 0.75 above $20 \mathrm{~km}$ but in some cases down to $10 \mathrm{~km}$. We show comparisons in the $10-60 \mathrm{~km}$ range keeping in mind that profiles below $20 \mathrm{~km}$ are averaged over a smaller number of profiles. Numbers of profiles indicated on the different figures concern the $20-60 \mathrm{~km}$ range. The OSIRIS data are converted in volume mixing ratio (VMR) units by using the ECMWF $(\mathrm{P}, \mathrm{T})$ fields provided in the Odin products.

Odin and POAM III Profiles are linearly interpolated as a function of log-pressure, to the fixed SMR/v222 2-km grid. We compare SMR/OSIRIS and POAM III profile by profile with the selected criteria before calculating for each instruments, 12 monthly mean profiles weighted by the total error (measurement noise and systematic errors). Calculations are made from January to December, over the whole period: 45 months from November 2001 to July 2005. As POAM III is 

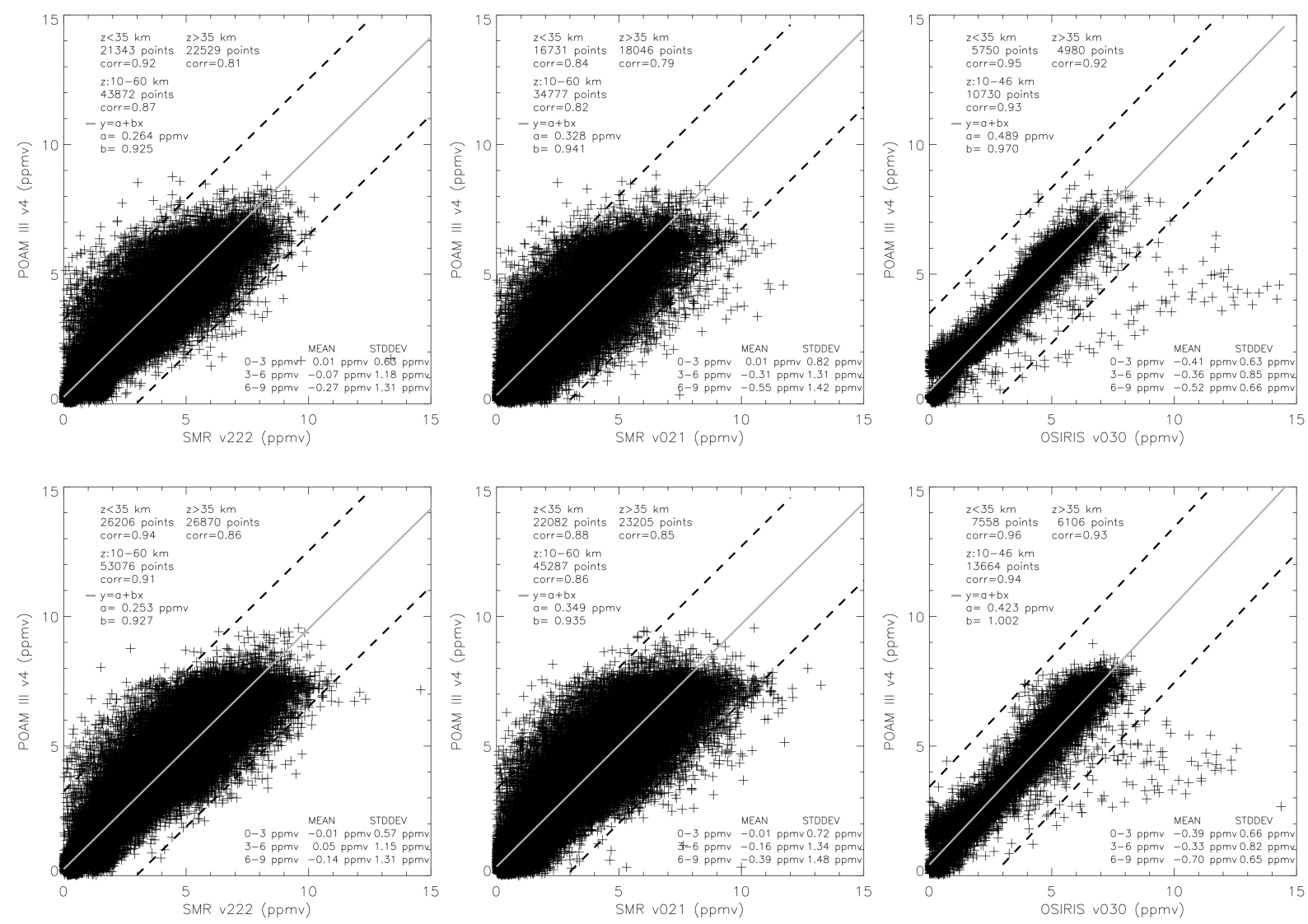

Fig. 2. Scatterplot of Odin/SMR and OSIRIS $\mathrm{O}_{3}$ versus POAM III measurements. Left: Odin/SMR v222 data; middle: Odin/SMR v2.1 data; right: Odin/OSIRIS v3.0 data. Top: Southern Hemisphere; bottom: Northern Hemisphere. Mean differences and standard deviations are indicated for the different ranges of the $\mathrm{O}_{3}$ mixing ratio. The dotted lines delimit deviations of \pm 3 ppmv for clarity. The solid gray line indicates the linear fit to the data.

a solar occultation instrument, measurements are constrained to relatively narrow latitudinal bands. Consequently, most of the coincidences between POAM III and Odin measurements occurred in the high latitude, sunlit hemispheres.

Comparisons are performed separately for satellite sunrise and sunset occultations. Note that all POAM sunrise occultations occur in the Northern Hemisphere (NH) whereas all POAM sunset occultations occur in the Southern Hemisphere (SH). Local times for the POAM measurements correspond to local sunsets throughout the year in the $\mathrm{NH}$, to local sunrise in the SH from April through August, and to local sunset in the SH from September through March. We have studied separately two ranges of altitudes (10-35 km and 35-60 km) to detect a possible altitude discrepancy.

We have applied our coincidence criteria successively to the SMR v222, SMR v2.1 and OSIRIS v3.0 profiles. Considering that the quality of the different ozone profiles is independent, the number of coincidences varies in terms of instruments and retrieval methods. As OSIRIS measurements are constrained to the illuminated hemisphere no coincidence is found during winter seasons. This explains the lowest number of coincidences found in the OSIRIS comparisons compared to the SMR comparisons, throughout the validation study. The total number of monthly coincidences between SMR and POAM III varies from 40 in September in the Southern Hemisphere to 368 in January in the Northern Hemisphere. For OSIRIS and POAM III comparison coincidences vary from 41 in October to 171 in March in the Northern Hemisphere. A summary of OSIRIS/SMR/POAM III annually and monthly coincidences is given in Table 1. In this table we show the absolute difference between the Odin and POAM III measurements considered as references. The numbers in the Table 1 represent the mean and standard deviation of the absolute difference profiles for the two range of altitudes: $10-35 \mathrm{~km}$ and $35-48$ or $60 \mathrm{~km}$.

In order to evaluate the Odin data quality against POAM III data, we combine all data in the form of a scatterplot. Results are plotted in Fig. 2. Each point in the scatterplot shows an ozone mixing ratio measured by Odin (SMR or OSIRIS instrument) and the corresponding measurement reported by the comparison instrument irregardless of the altitude associated with the pair of measurements. Negative values due to measurement noise are not shown in this figure but are used for the fit. For a more quantitative estimation of the 
Table 1. Comparisons POAM III/Odin for the period November 2001 to July 2005 for Northern and Southern high-latitude measurements. (1) Mean latitude and spatial dispersion. (2) Number of profiles used for the POAM III/Odin comparisons for the different versions SMR/v222, SMR/v2.1 and OSIRIS/v3.0. (3)(4)(5) Averages $\left(\Delta X=\frac{1}{n} \sum_{i=1}^{n} \Delta X_{i}\right)$ and standard deviations (stddev $\left.=\sqrt{\frac{1}{n-1} \sum_{i=1}^{n}\left(\Delta X_{i}^{2}-\Delta^{-} X^{2}\right.}\right)$, number in brackets) of the absolute difference $(\Delta X=$ Odin-POAM III) are given over the two height ranges $10-35 \mathrm{~km}$ and $35-60 \mathrm{~km}$.

\begin{tabular}{|c|c|c|c|c|c|c|c|c|}
\hline \multicolumn{9}{|c|}{ Southern Hemisphere } \\
\hline \multirow[t]{2}{*}{ Month } & \multirow[t]{2}{*}{ (1) Latitude } & \multirow[t]{2}{*}{ (2) $\mathrm{v} 222 / \mathrm{v} 2.1 / \mathrm{v} 3.0$} & \multicolumn{2}{|c|}{ (3) v3.0-POAM III } & \multicolumn{2}{|c|}{ (4) v222-POAM III } & \multicolumn{2}{|c|}{ (5) v2.1-POAM III } \\
\hline & & & $10-35 \mathrm{~km}$ & $35-48 \mathrm{~km}$ & $10-35 \mathrm{~km}$ & $35-60 \mathrm{~km}$ & $10-35 \mathrm{~km}$ & $35-60 \mathrm{~km}$ \\
\hline January & $-64.4^{\circ} \pm 1.3^{\circ}$ & $218 / 186 / 78$ & $-0.34(0.24)$ & $-0.53(0.15)$ & $0.05(0.14)$ & $-0.40(0.11)$ & $-0.12(0.30)$ & $-0.46(0.12)$ \\
\hline February & $-72.0^{\circ} \pm 3.0^{\circ}$ & $192 / 171 / 113$ & $-0.23(0.16)$ & $-0.52(0.12)$ & $0.10(0.18)$ & $-0.40(0.11)$ & $-0.08(0.20)$ & $-0.46(0.16)$ \\
\hline March & $-83.7^{\circ} \pm 2.6^{\circ}$ & $170 / 134 / 0$ & $-0.12(0.21)$ & $0.20(0.20)$ & $0.12(0.28)$ & $-0.08(0.26)$ & $-0.01(0.17)$ & $-0.21(0.10)$ \\
\hline April & $-79.6^{\circ} \pm 3.3^{\circ}$ & $153 / 131 / 0$ & & & $0.13(0.33)$ & $0.07(0.40)$ & $-0.07(0.21)$ & $-0.02(0.30)$ \\
\hline May & $-70.4^{\circ} \pm 2.3^{\circ}$ & $94 / 88 / 0$ & & & $-0.00(0.29)$ & $-0.04(0.61)$ & $-0.14(0.14)$ & $0.06(0.48)$ \\
\hline June & $-67.6^{\circ} \pm 1.5^{\circ}$ & $167 / 121 / 0$ & & & $0.12(0.37)$ & $-0.26(0.65)$ & $-0.20(0.15)$ & $0.05(0.54)$ \\
\hline July & $-65.5^{\circ} \pm 0.4^{\circ}$ & $80 / 70 / 0$ & & & $-0.04(0.33)$ & $0.08(0.51)$ & $-0.21(0.15)$ & $0.21(0.40)$ \\
\hline August & $-76.1^{\circ} \pm 2.9^{\circ}$ & $117 / 89 / 0$ & & & $-0.03(0.44)$ & $0.05(0.43)$ & $-0.14(0.14)$ & $0.01(0.18)$ \\
\hline September & $-85.7^{\circ} \pm 2.0^{\circ}$ & $40 / 21 / 0$ & & & $0.19(0.44)$ & $-0.42(0.20)$ & $-0.08(0.21)$ & $-0.35(0.17)$ \\
\hline October & $-80.2^{\circ} \pm 3.3^{\circ}$ & $150 / 96 / 59$ & $-0.05(0.28)$ & $-0.42(0.19)$ & $0.23(0.29)$ & $-0.32(0.12)$ & $0.14(0.28)$ & $-0.40(0.08)$ \\
\hline November & $-69.9^{\circ} \pm 2.5^{\circ}$ & $188 / 152 / 120$ & $-0.35(0.21)$ & $-0.58(0.14)$ & $0.17(0.16)$ & $-0.33(0.16)$ & $-0.11(0.20)$ & $-0.39(0.12)$ \\
\hline December & $-63.7^{\circ} \pm 0.9^{\circ}$ & $175 / 152 / 75$ & $-0.32(0.21)$ & $-0.55(0.17)$ & $0.16(0.19)$ & $-0.32(0.13)$ & $-0.07(0.17)$ & $-0.40(0.10)$ \\
\hline Annual & $-73.4^{\circ} \pm 7.7^{\circ}$ & $1744 / 1411 / 456$ & $-0.12(0.31)$ & $-0.10(0.12)$ & $-0.09(0.23)$ & $-0.19(0.17)$ & $-0.10(0.15)$ & $-0.20(0.10)$ \\
\hline \multicolumn{9}{|c|}{ Northern Hemisphere } \\
\hline \multirow[t]{2}{*}{ Month } & \multirow[t]{2}{*}{ Latitude } & \multirow[t]{2}{*}{$\mathrm{v} 222 / \mathrm{v} 2.1 / \mathrm{v} 3.0$} & \multicolumn{2}{|c|}{ v3.0-POAM III } & \multicolumn{2}{|c|}{ v222-POAM III } & \multicolumn{2}{|c|}{ v2.1-POAM III } \\
\hline & & & $10-35 \mathrm{~km}$ & $35-48 \mathrm{~km}$ & $10-35 \mathrm{~km}$ & $35-60 \mathrm{~km}$ & $10-35 \mathrm{~km}$ & $35-60 \mathrm{~km}$ \\
\hline January & $64.8^{\circ} \pm 0.8^{\circ}$ & $368 / 316 / 0$ & & & $0.13(0.31)$ & $-0.12(0.30)$ & $-0.02(0.20)$ & $-0.30(0.18)$ \\
\hline February & $67.1^{\circ} \pm 0.5^{\circ}$ & $224 / 210 / 20$ & $-0.26(0.32)$ & $-0.78(0.30)$ & $0.10(0.28)$ & $-0.06(0.40)$ & $-0.03(0.20)$ & $-0.21(0.20)$ \\
\hline March & $67.1^{\circ} \pm 0.6^{\circ}$ & $326 / 302 / 171$ & $-0.23(0.10)$ & $-0.83(0.10)$ & $0.11(0.26)$ & $-0.20(0.23)$ & $-0.05(0.14)$ & $-0.26(0.14)$ \\
\hline April & $63.5^{\circ} \pm 1.4^{\circ}$ & $112 / 105 / 77$ & $-0.23(0.17)$ & $-0.66(0.17)$ & $0.04(0.22)$ & $-0.28(0.13)$ & $-0.09(0.17)$ & $-0.31(0.17)$ \\
\hline May & $58.8^{\circ} \pm 1.4^{\circ}$ & $120 / 115 / 68$ & $-0.35(0.25)$ & $-0.81(0.29)$ & $0.06(0.26)$ & $-0.33(0.14)$ & $-0.09(0.14)$ & $-0.25(0.16)$ \\
\hline June & $55.1^{\circ} \pm 0.5^{\circ}$ & $74 / 63 / 44$ & $-0.40(0.29)$ & $-0.75(0.35)$ & $0.11(0.25)$ & $-0.31(0.14)$ & $0.06(0.29)$ & $-0.23(0.09)$ \\
\hline July & $55.6^{\circ} \pm 0.8^{\circ}$ & $177 / 150 / 82$ & $-0.33(0.26)$ & $-0.72(0.34)$ & $0.14(0.25)$ & $-0.38(0.12)$ & $-0.01(0.13)$ & $-0.29(0.11)$ \\
\hline August & $60.8^{\circ} \pm 2.1^{\circ}$ & $134 / 117 / 45$ & $-0.31(0.22)$ & $-0.62(0.22)$ & $0.18(0.20)$ & $-0.43(0.16)$ & $-0.06(0.17)$ & $-0.39(0.14)$ \\
\hline September & $67.9^{\circ} \pm 1.8^{\circ}$ & $77 / 66 / 50$ & $-0.24(0.16)$ & $-0.66(0.10)$ & $0.20(0.25)$ & $-0.24(0.17)$ & $0.04(0.19)$ & $-0.34(0.13)$ \\
\hline October & $70.6^{\circ} \pm 0.5^{\circ}$ & $101 / 73 / 41$ & $-0.12(0.12)$ & $-0.60(0.11)$ & $0.17(0.25)$ & $-0.10(0.31)$ & $0.02(0.21)$ & $0.14(0.28)$ \\
\hline November & $66.9^{\circ} \pm 1.3^{\circ}$ & $148 / 124 / 0$ & & & $0.18(0.21)$ & $0.03(0.42)$ & $-0.03(0.22)$ & $-0.05(0.24)$ \\
\hline December & $63.8^{\circ} \pm 0.4^{\circ}$ & $225 / 182 / 0$ & & & $0.28(0.38)$ & $0.06(0.26)$ & $0.11(0.21)$ & $-0.05(0.17)$ \\
\hline Annual & $63.5^{\circ} \pm 4.8^{\circ}$ & $2071 / 1808 / 603$ & $-0.39(0.22)$ & $-0.54(0.12)$ & $0.09(0.26)$ & $-0.20(0.21)$ & $-0.05(0.11)$ & $-0.23(0.12)$ \\
\hline
\end{tabular}

systematic effects in the data, the mean and the standard deviation of the (Odin-POAM III) differences are calculated for each SMR and OSIRIS version for the three ranges of ozone mixing ratio: 0-3 ppmv, 3-6 ppmv and 6-9 ppmv. For the low mixing ratios of ozone (range 0-3 ppmv), i.e. the extreme lower and higher altitudes, we find a standard deviation smaller than 0.7, 0.8 and 0.7 ppmv for version SMR v222, SMR v2.1 and OSIRIS v3.0, respectively. SMR retrievals show here similar mixing ratios (difference: $\pm 0.01 \mathrm{ppmv}$ ) as the POAM III measurements whereas OSIRIS profiles show smaller values (difference: $-0.4 \mathrm{ppmv}$ ). In the intermediate range (3-6 ppmv), SMR measurements are in general lower than POAM III mixing ratios (difference: \pm 0.05 ppmv for v222 data, $\sim 0.3$ ppmv for v2.1 data) and the standard devi- ation is of the order of $1.2 \mathrm{ppmv}$ for the v2.1 data and 1.35 ppmv for the v222 data. OSIRIS profiles show lower mixing ratio (difference: $-0.35 \mathrm{ppmv}$ ) than the POAM III measurements with a standard deviation of $0.85 \mathrm{ppmv}$. In the greatest ozone mixing ratio range (6-9 ppmv), corresponding to the ozone peak vicinity, SMR profiles still exhibit lower mean values of the order of $0.1-0.3 \mathrm{ppmv}$ for v222 and $0.4-0.6 \mathrm{ppmv}$ for v2.1 data. We find a standard deviation smaller than $1.4 \mathrm{ppmv}$ and $1.5 \mathrm{ppmv}$ for the SMR v222 and v2.1 versions respectively. OSIRIS profiles also show lower values (difference: $\sim 0.6 \mathrm{ppmv}$ ) with a standard deviation below $0.7 \mathrm{ppmv}$. In general, smaller standard deviations are found for OSIRIS v3.0 and SMR v222 data. Nevertheless OSIRIS results show a larger difference compared to the 

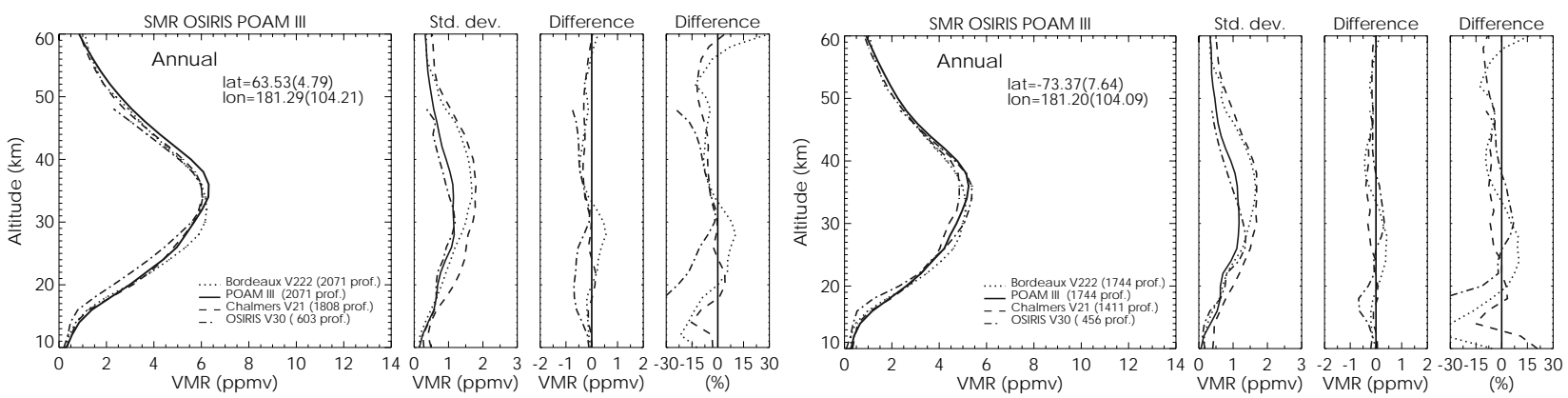

Fig. 3. Zonal mean comparisons between SMR/v222, SMR/v2.1, OSIRIS/v3.0 and POAM III/v4.0 ozone profiles performed for the period November 2001 to July 2005 for the Northern (left) and Southern (right) Hemispheres. The left plot shows the mean of coincident profiles for SMR/v222 (dotted), SMR/v2.1 (dashed), OSIRIS/v3.0 (dashed-dotted) and POAM III (solid). Error bars represent the calculated total error from $n$ individual total errors: $\sigma(z)^{2}=\sum_{i=0}^{n} \sigma_{i}(z)^{2}$. In annual comparisons the total error is within the line thickness. The three other plots show respectively the standard deviation in VMR (ppmv), the absolute (Odin - POAM III) and relative ((Odin - POAM III)/POAM III $x$ 100) difference expressed in VMR (ppmv) and percentage, respectively. The number of coincident profiles used for the comparisons and the latitude-longitude coverage are indicated.

SMR versions. In summary, Odin data agree well with the POAM III v4.0 data in terms of standard deviation, within 1.5 ppmv (v2.1), $1.3 \mathrm{ppmv}$ (v222) and $0.7 \mathrm{ppmv}$ (v3.0) in the whole exploitable range. We also calculate correlation coefficients in two ranges of altitudes: $10-35 \mathrm{~km}$ and $35-48 / 60$ (OSIRIS/SMR) km. The last results (shown in Fig. 2) are confirmed by these correlation coefficients which are systematically larger for the OSIRIS data $(\sim 0.95)$ compared to the SMR v222 $(\sim 0.9)$ and the SMR v2.1 $(\sim 0.85)$ data, reflecting mainly the noise in the individual mixing ratios.

To refine quantitatively our comparisons we calculate zonal average profiles for both latitude ranges over the complete period (cf. Fig. 3) and over 6 selected months (cf. Figs. 4 and 5). These plots show the really good agreement between Odin and POAM III profiles though both missions use different techniques and algorithms. In the annual comparisons (cf. Fig. 3) 2071 POAM III profiles in the Northern Hemisphere and 1744 POAM III profiles in the Southern Hemisphere are compared to the mean profiles. The first characteristic is the systematically lower values of the Odin profiles with respect to POAM III profiles: OSIRIS $(-0.4 \pm 0.2 \mathrm{ppmv})$, SMR v2.1 $(-0.1 \pm 0.15 \mathrm{ppmv})$ in the $10-35 \mathrm{~km}$ range. The SMR v222 data do not show a systematic tendency with a $0.1 \pm 0.2$ ppmv bias in the Northern Hemisphere and a $-0.1 \pm 0.2$ ppmv bias in the Southern Hemisphere. In the $35-60 \mathrm{~km}$ range the Odin profiles show the same feature: OSIRIS $(-0.6 \pm 0.1 \mathrm{ppmv})$, SMR v222 $(-0.2 \pm 0.2 \mathrm{ppmv})$, SMR v2.1 $(-0.2 \pm 0.1 \mathrm{ppmv}))$.

Such annual comparisons are confirmed by the monthly comparisons shown in Figs. 4 and 5. OSIRIS and POAM III monthly profiles agree within $0.4 \pm 0.3$ ppmv between 10 and $35 \mathrm{~km}$ and within $0.8 \pm 0.3 \mathrm{ppmv}$ above $35 \mathrm{~km}$ in both hemispheres (Table 1). A negative bias is observed at all altitudes between OSIRIS and POAM III. It is consistent with the error analysis performed by Von Savigny et al. (2003) who have demonstrated that the OSIRIS retrieval method is less sensitive to ozone above $40 \mathrm{~km}$. For OSIRIS, there is a know underestimation at higher altitudes that does not appear to be associated with a pointing problem, but rather a retrieval problem. There is, however, what seems to be a pointing problem in the May-July period (likely in some way related to satellite eclipse) as well as at other sporadic times during the mission. See McLinden et al. (2007) for more information.

The POAM III monthly profiles are closer to the SMR profile structures and especially to the v2.1 data with an agreement within $-0.2 \pm 0.15$ ppmv between 10 and $35 \mathrm{~km}$ and within $-0.4 \pm 0.2 \mathrm{ppmv}$ between 35 and $60 \mathrm{~km}$. The SMR/v222 retrievals systematically overestimate the ozone amounts below $35 \mathrm{~km}$ with a positive bias of $0.3 \pm 0.3 \mathrm{ppmv}$. In the 35-60 km range the SMR/v222 data show the same agreement of $-0.4 \pm 0.2 \mathrm{ppmv}$ as the SMR/v2.1 data. Such a positive bias $(\leq 10 \%)$ has already been detected below $10 \mathrm{hPa}$ $(\sim 32 \mathrm{~km}$ ), between SMR/v222 and MLS/v1.5 (Microwave Limb Sounder (Aura Satellite)) ozone profiles by Barret et al. (2006).

An additional feature of the comparisons is the discrepancy with respect to the maximum ozone altitude. In both hemispheres this altitude is systematically displaced to lower altitudes by $1-3 \mathrm{~km}$ for OSIRIS and SMR/v2.1 and by $1-$ $5 \mathrm{~km}$ for SMR/v222 compared to POAM III. This offset could not be explained by the well-known Odin random error of 100-300 meters at the observed tangent point. This discrepancy was already highlighted during the initial OSIRIS ozone validation (Petelina et al., 2004, 2005). We have used OSIRIS v3.0 data based on reconstructed orbit data. Nevertheless an altitude offset of the ozone peak is again detected in OSIRIS data. In addition, most plots exhibit higher POAM III ozone values from the ozone maximum up to the mesosphere. The two SMR products are very similar from the ozone maximum to the top altitude $(60 \mathrm{~km})$ of the comparisons. In this altitude range POAM III profiles are in general 

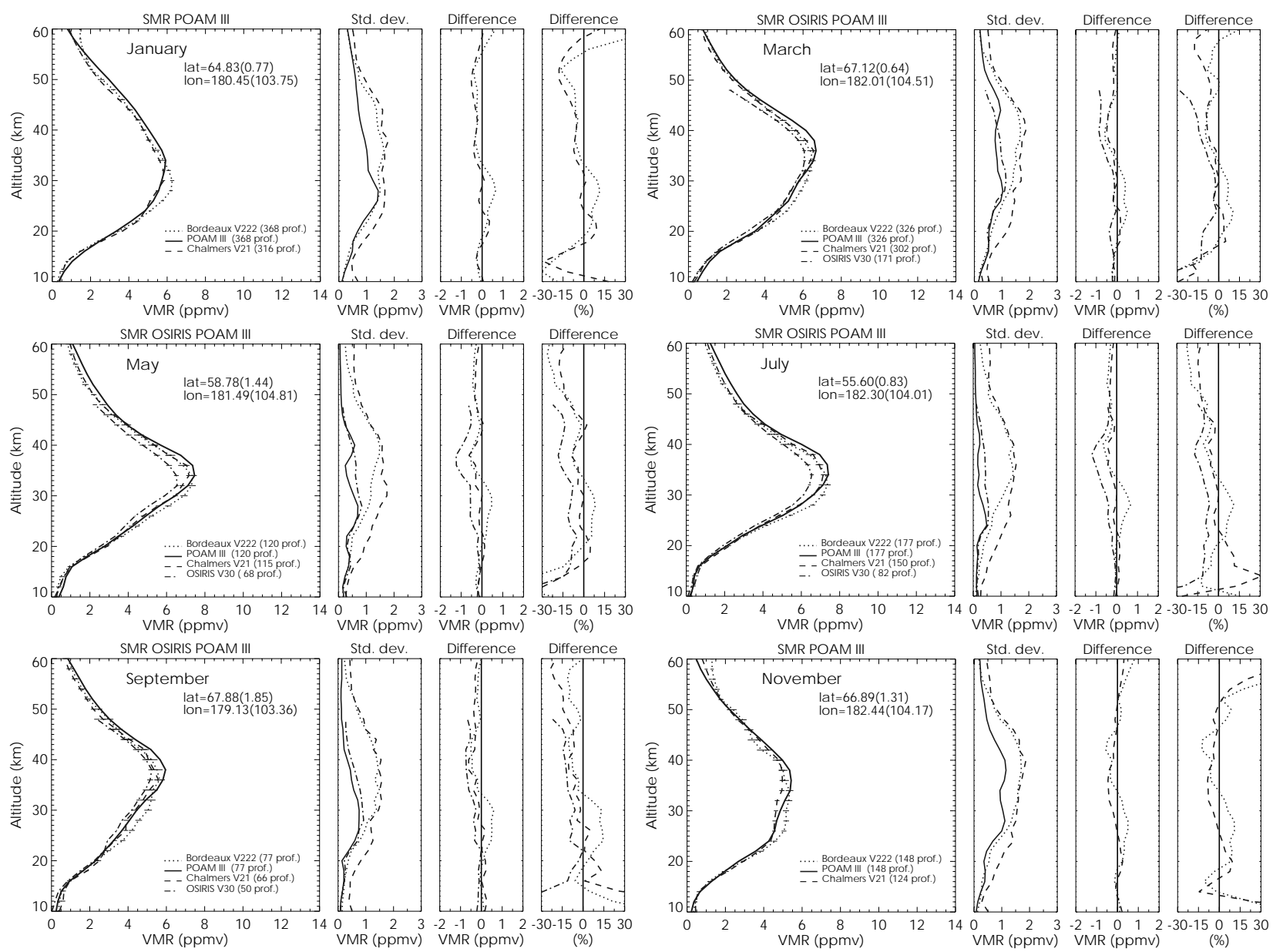

Fig. 4. Same as Fig. 3 but for monthly mean comparisons between ozone SMR/v222, SMR/v2.1, OSIRIS/v3.0 and POAM III/v4.0 coincident profiles performed for January, March, May, July, September and November for the full dataset in the Northern high latitudes $63.5^{\circ}\left( \pm 4.8^{\circ}\right)$.

$\sim 0.5$ ppmv larger than SMR profiles. This difference is reduced in the winter Northern Hemisphere (October-March) and reversely in the Southern Hemisphere (April-August) with a 0.5 ppmv positive bias between 45 and $60 \mathrm{~km}$. From the ozone maximum to $48 \mathrm{~km}$, the OSIRIS profiles follow quite well the SMR profiles with a slightly negative bias, maximal in the summer Northern Hemisphere (0.5-1 ppmv). This feature does not exist in the Southern Hemisphere. The new ozone retrieval code for OSIRIS, SaskMART, recently developed at the University of Saskatchewan could be the opportunity to investigate the origin of this discrepancy.

In summary, the Odin measurements and the POAM III ozone peak altitude are shifted by a few kilometres which create a difference in amplitude which continues up to the mesosphere. Odin SMR and OSIRIS maximum ozone peak values are mostly of the order of $0.5-1$ ppmv smaller than POAM III values and located a few kilometres lower, but not in a systematic way. This feature continues up to the mesosphere with seasonal and hemispheric differences. In general, the Odin and POAM III measurements agree in monthly mean comparisons within $-0.5 \pm 0.2 \mathrm{ppmv}$ (OSIRIS) and
$-0.3 \pm 0.2$ ppmv (SMR). SMR profiles do not show any altitude range with systematic discrepancy except the v222 positive bias in the $20-30 \mathrm{~km}$ range. The SMR v2.1 profiles are the Odin products which present the best overall agreement with POAM III profiles from the lower stratosphere to the mesosphere, in both hemispheres.

\section{Ground-based and balloon-borne measurements}

\subsection{Measurement sites}

Ground-based and balloon-borne data used for Odin SMR validation have a dual origin. First, we use experiment data pertaining to the NDACC. NDACC is a set of high-quality remote sensing research stations for the observation and understanding the physical and chemical state of the atmosphere. Ozone and key ozone-related chemical compounds and parameters are targeted for measurements. NDACC is a major component of the international upper atmosphere research effort. One of the principal goals of the network is to provide 

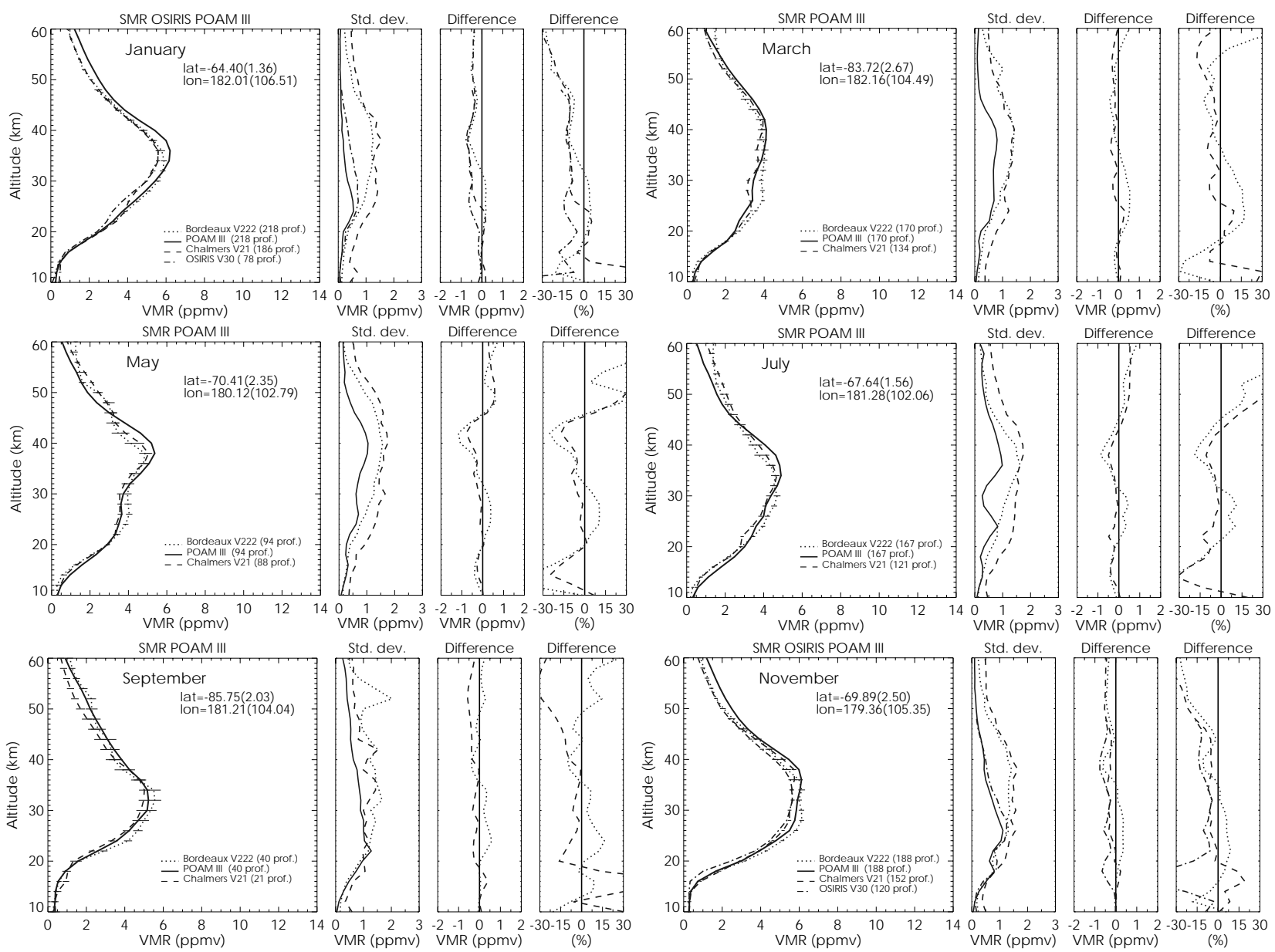

Fig. 5. Same as Fig. 4 but for monthly mean comparisons between ozone SMR/v222, SMR/v2.1, OSIRIS/v3.0 and POAM III/v4.0 coincident profiles performed for January, March, May, July, September and November for the full dataset in the Southern high latitudes $-73.4^{\circ}\left( \pm 7.7^{\circ}\right)$.

independent calibrations and validations of space-based sensors of the atmosphere and to make complementary measurements. The ground-based instruments used in the following comparisons are: (1) ozone lidars, (2) ozone microwave radiometers and (3) ozone sondes.

The NDACC brings together 87 stations dispersed in both hemispheres with prominent weight in the Northern midlatitudes. We selected 32 stations (12 primary stations, 20 complementary stations). In Table 2 we give information about all selected stations: location, technique employed, number and range of selected dates, vertical range of comparison and the number of profiles retained. Sometimes a few Odin profiles are missing due to the poor quality of the observations or non-existent data. In general the available measurements for the comparisons spread over one to four years from November 2001 to July 2005.

Second, other data used for SMR validation were obtained by selective balloon-borne experiments. Three balloon-flights, AMON, SALOMON and SPIRALE were conducted by the Laboratoire of Physique et Chimie de l'Environnement (Orléans, France)) in Kiruna (Sweden) and Aire sur 1'Adour (France). We also use data from the
MANTRA 2002 campaign performed in Vanscoy (Canada) by the Canadian Space Agency and observations from two $\mathrm{SAOZ}$ flights conducted in Bauru (Brasil) by the Service d'Aéronomie (France). We summarise characteristics of these experiments at the end of Table 2. Figure 6 shows the selected NDACC stations and the five balloon flight site locations.

A selection for the Odin products based on the quality flag has also been done. For both sets of data we have compared ozone profiles over the largest possible range of altitudes. In general, SMR profiles are significant above the altitude $15-20 \mathrm{~km}$ and the NDACC observations do not really exceed $40 \mathrm{~km}$ for ozone sonde experiments, $50 \mathrm{~km}$ and $60 \mathrm{~km}$ respectively for lidar and microwave measurements. The maximum altitude of the balloon-borne ozone profiles is comprised between 29 and $36 \mathrm{~km}$. So, we have validated SMR profiles with ground-based and balloon-borne observations over different altitude ranges from $15-20 \mathrm{~km}$ to $60 \mathrm{~km}$. All plots are respectively gathered in Figs. 7 and 8 for the NDACC and in Figs. 10, 11, and 12 for the balloon flight inter-comparisons. 
Table 2. Information about (a) the NDACC instruments and (b) balloon flight sites, employed techniques, number of coincidences and periods of the inter-comparisons. * M-W: micro-wave technique.

(a) NDACC sites

\begin{tabular}{|c|c|c|c|c|c|}
\hline Station & Techique & Coordinates & \# of profiles & Upper altitude $(\mathrm{km})$ & Temporal range \\
\hline Alert, Canada & Sonde & $82.5^{\circ} \mathrm{N} 117.7^{\circ} \mathrm{W}$ & 26 & 48 & $16 / 01 / 2002-23 / 06 / 2004$ \\
\hline Andoya, Norway & Lidar & $69.3^{\circ} \mathrm{N} 16^{\circ} \mathrm{E}$ & 35 & 48 & $17 / 01 / 2002-05 / 01 / 2005$ \\
\hline Bern, Switzerland & $\mathrm{M}-\mathrm{W}^{*}$ & $46.9^{\circ} \mathrm{N} 7.4^{\circ} \mathrm{E}$ & 1394 & 58 & $09 / 11 / 2001-31 / 10 / 2003$ \\
\hline Bordeaux, France & $\mathrm{M}-\mathrm{W}$ & $44.8^{\circ} \mathrm{N} 0.4^{\circ} \mathrm{W}$ & 191 & 57 & $09 / 11 / 2001-23 / 05 / 2003$ \\
\hline Boulder, USA & Sonde & $40.0^{\circ} \mathrm{N} 74.7^{\circ} \mathrm{W}$ & 39 & 36 & $07 / 12 / 2001-24 / 06 / 2005$ \\
\hline Debilt, The Netherlands & Sonde & $52.1^{\circ} \mathrm{N} 5.2^{\circ} \mathrm{E}$ & 52 & 34 & $22 / 11 / 2001-07 / 07 / 2005$ \\
\hline Dumont D’Urville, Antarctica & Sonde & $66.4^{\circ} \mathrm{S} 140.0^{\circ} \mathrm{E}$ & 26 & 32 & $04 / 07 / 2002-25 / 06 / 2005$ \\
\hline Eureka, Canada & Sonde & $80.0^{\circ} \mathrm{N} 86.4^{\circ} \mathrm{W}$ & 22 & 46 & $24 / 12 / 2001-21 / 07 / 2005$ \\
\hline Hilo, Hawaii USA & Sonde & $19.7^{\circ} \mathrm{N} 155.1^{\circ} \mathrm{W}$ & 40 & 46 & $31 / 2001 / 02-19 / 05 / 2005$ \\
\hline Hohenpeissenberg, Germany & Sonde & $47.8^{\circ} \mathrm{N} 11.0^{\circ} \mathrm{E}$ & 98 & 46 & 09/11/2001-26/07/2004 \\
\hline id. & Lidar & id. & 97 & 46 & $31 / 01 / 2002-19 / 05 / 2005$ \\
\hline Izana, Tenerife Spain & Sonde & $28.3^{\circ} \mathrm{N} 16.5^{\circ} \mathrm{W}$ & 36 & 34 & $28 / 11 / 2001-05 / 01 / 2005$ \\
\hline Lauder, New Zealand & Lidar & $45.04^{\circ} \mathrm{S} 169.68^{\circ} \mathrm{E}$ & 48 & 48 & $09 / 12 / 2001-11 / 12 / 2004$ \\
\hline id. & $\mathrm{M}-\mathrm{W}$ & id. & 461 & 60 & $25 / 12 / 2001-07 / 07 / 2005$ \\
\hline id. & Sonde & id. & 48 & 32 & $03 / 11 / 2001-06 / 10 / 2004$ \\
\hline Legionowo, Poland & Sonde & $52.4^{\circ} \mathrm{N} 21.0^{\circ} \mathrm{E}$ & 16 & 36 & $21 / 11 / 2001-24 / 11 / 2004$ \\
\hline McMurdo, Antarctica & Sonde & $77.8^{\circ} \mathrm{S} 166.6^{\circ} \mathrm{E}$ & 2 & 30 & $26 / 09 / 2003-06 / 10 / 2004$ \\
\hline Mauna Loa, Hawaii USA & Lidar & $19.5^{\circ} \mathrm{N} 155.6^{\circ} \mathrm{W}$ & 98 & 58 & $21 / 11 / 2001-16 / 06 / 2005$ \\
\hline id. & M-W & id. & 779 & 58 & $03 / 12 / 2001-22 / 07 / 2005$ \\
\hline Natal, Brazil & Sonde & $5.9^{\circ} \mathrm{S} 35.2^{\circ} \mathrm{W}$ & 98 & 32 & $06 / 11 / 2001-29 / 03 / 2005$ \\
\hline Neumayer, Antarctica & Sonde & $70.6^{\circ} \mathrm{S} 8.4^{\circ} \mathrm{E}$ & 69 & 32 & $21 / 11 / 2001-04 / 05 / 2005$ \\
\hline Ny Alesund, Spitsberg & Lidar & $78.9^{\circ} \mathrm{N} 11.9^{\circ} \mathrm{E}$ & 48 & 50 & $28 / 11 / 2001-24 / 11 / 2004$ \\
\hline id. & $\mathrm{M}-\mathrm{W}$ & id. & 1585 & 54 & $01 / 02 / 2002-30 / 11 / 2003$ \\
\hline id. & sonde & id. & 94 & 34 & $21 / 11 / 2001-05 / 05 / 2005$ \\
\hline OHP, France & Lidar & $43.5^{\circ} \mathrm{N} 5^{\circ} 4^{\prime} \mathrm{E}$ & 115 & 46 & $21 / 11 / 2001-16 / 06 / 2005$ \\
\hline Paramaribo, Suriname & Sonde & $5.75^{\circ} \mathrm{N} 55.2^{\circ} \mathrm{W}$ & 42 & 32 & $21 / 11 / 2001-06 / 07 / 2005$ \\
\hline Payerne, Switzerland & Sonde & $46.82^{\circ} \mathrm{N} 6.9^{\circ} \mathrm{E}$ & 147 & 34 & $09 / 11 / 2001-13 / 05 / 2005$ \\
\hline id. & M-W & id. & 4022 & 58 & 07/01/2004-26/01/2005 \\
\hline Prague, Czech Republic & Sonde & $50.0^{\circ} \mathrm{N} 14.4^{\circ} \mathrm{E}$ & 11 & 34 & $16 / 01 / 2004-05 / 01 / 2005$ \\
\hline Samoa Islands & Sonde & $14.2^{\circ} \mathrm{S} 189.4^{\circ} \mathrm{E}$ & 28 & 38 & $10 / 11 / 2001-19 / 05 / 2005$ \\
\hline Scoresbysund, Greenland & Sonde & $70.5^{\circ} \mathrm{N} 158.0^{\circ} \mathrm{W}$ & 43 & 34 & $09 / 11 / 2001-05 / 01 / 2005$ \\
\hline Sodankyla, Finland & Sonde & $67.4^{\circ} \mathrm{N} 26.7^{\circ} \mathrm{E}$ & 36 & 36 & $21 / 11 / 2001-04 / 08 / 2004$ \\
\hline South Pole, Antarctica & Sonde & $90^{\circ} \mathrm{S}$ & 16 & 32 & 19/09/2002-10/10/2004 \\
\hline Table Mountain, USA & Lidar & $34.4^{\circ} \mathrm{N} 117.7^{\circ} \mathrm{W}$ & 1161 & 58 & $10 / 11 / 2001-16 / 06 / 2005$ \\
\hline Thule, Greenland & Sonde & $76.5^{\circ} \mathrm{N} 68.7^{\circ} \mathrm{W}$ & 16 & 34 & 08/03/2002-24/09/2004 \\
\hline id. & M-W & id. & 19 & 58 & $25 / 01 / 2002-21 / 02 / 2003$ \\
\hline Tsukuba, Japan & Lidar & $36.0^{\circ} \mathrm{N} 140.1^{\circ} \mathrm{E}$ & 20 & 38 & $27 / 11 / 2001-05 / 01 / 2005$ \\
\hline Uccle, Belgium & Sonde & $50.8^{\circ} \mathrm{N} 4.3^{\circ} \mathrm{E}$ & 123 & 32 & 09/11/2001-05/01/2005 \\
\hline Wallops Island, USA & Sonde & $38.9^{\circ} \mathrm{N} 76.7^{\circ} \mathrm{W}$ & 51 & 34 & $21 / 11 / 2001-06 / 07 / 2005$ \\
\hline
\end{tabular}

(b) Balloon-borne experiment sites

\begin{tabular}{|c|c|c|c|c|c|}
\hline Launch site & Technique & Coordinates & \# of profiles & Upper altitude $(\mathrm{km})$ & Balloon-launch dates \\
\hline Aire sur 1'Adour, France & balloon & $43.4^{\circ} \mathrm{N} 0.1^{\circ} \mathrm{W}$ & 2 & $32-36$ & 19/09/2002-02/10/2002 \\
\hline Kiruna, Sweden & balloon & $67.5^{\circ} \mathrm{N} 21.0^{\circ} \mathrm{E}$ & 3 & $27-33$ & $\begin{array}{l}21 / 01 / 2003-01 / 03 / 2003 \\
20 / 01 / 2006\end{array}$ \\
\hline Vanscoy, Canada & balloon & $52.0^{\circ} \mathrm{N} 107.0^{\circ} \mathrm{W}$ & 5 & $26-38$ & $15 / 08 / 2002-02 / 09 / 2002$ \\
\hline Teresina, Brasil & balloon & $5.0^{\circ} \mathrm{N} 43.2^{\circ} \mathrm{W}$ & 1 & 33 & $22 / 06 / 2005$ \\
\hline Bauru, Brasil & balloon & $22.3^{\circ} \mathrm{S} 49.0^{\circ} \mathrm{W}$ & 1 & 29 & $18 / 02 / 2003-31 / 01 / 2004$ \\
\hline
\end{tabular}


A statistical analysis of comparisons between Odin retrievals from SMR (CTSO/version 222, Chalmers/version 2.1), OSIRIS (version 3.0) and NDACC has been performed with different coincidence criteria. Since NDACC measurements are in general only conducted daily (except lidar and microwave measurements), we chose a broad time range coincidence criteria of less than $12 \mathrm{~h}$, but the same spatial coincidence criteria of $\leq 5^{\circ}$ in latitude and $\leq 10^{\circ}$ in longitude as in the POAM III study. The time criterion has been extended to 1-3 days to find Odin/balloon-borne mission coincidences. Considering the average stratospheric wind speeds, the Odin satellite has a reasonable probability of encountering the same airmass measured by the ground-based and balloonborne instruments within this time-distance criterion. However, under polar vortex conditions, large differences in the mixing ratios inside and outside the vortex are found. Consequently, in the case of individual profile comparisons, great care has been taken in comparing ozone profiles only when they are either both inside or both outside the polar vortex.

We recall that limb profiles are usually the intrinsic average along the observational line of sight, which sets a limitation to the horizontal resolution of the measurements. The Earth's limb is viewed in the flight direction covering about $500-1000 \mathrm{~km}$ around the tangent point.

\subsection{NDACC observations}

\subsubsection{Techniques}

Ozone sondes are launched more or less regularly on board of small meteorological balloons and yield the vertical distribution of ozone volume mixing ratio (VMR) from the ground up to the burst point $(\sim 30 \mathrm{~km})$. Ozone VMR recorded at a typical vertical resolution of $100-150 \mathrm{~m}$ is converted into ozone number density using pressure and temperature data recorded onboard the same balloon. Typical error estimates are: systematic error from 3\% (0-20 km) to 5\% (20-35 km); precision from 5\% $(0-20 \mathrm{~km})$ to $7 \%(20-35 \mathrm{~km})$ (De Clercq et al., 2007).

To observe upper stratospheric ozone, most NDACC stations use either Differential Absorption Lidar (DIAL) or microwave radiometer systems. DIAL systems measure the ozone absorption of an atmospheric layer by comparing atmospheric return signals from the top and bottom of the layer, at two (or more) wavelengths (Pelon and Mégie, 1982). A summary of many validation exercises within the NDACC framework (Keckhut et al., 2004) shows that the accuracy of a typical stratospheric ozone profile measured by lidar is approximately $3 \%$ at $35 \mathrm{~km}$, and $10 \%$ at $40 \mathrm{~km}$, depending on averaging time, system power, and other factors (McDermid et al., 1998; McPeters et al., 1999). Altitude resolution is of the order of $1 \mathrm{~km}$ at $30 \mathrm{~km}$ altitude and $5 \mathrm{~km}$ at $40 \mathrm{~km}$ (Godin et al., 1999; Keckhut et al., 2004). Precision and altitude resolution become poorer with increasing altitude. Most systems do not provide reliable data above 50 to $55 \mathrm{~km}$. Li-

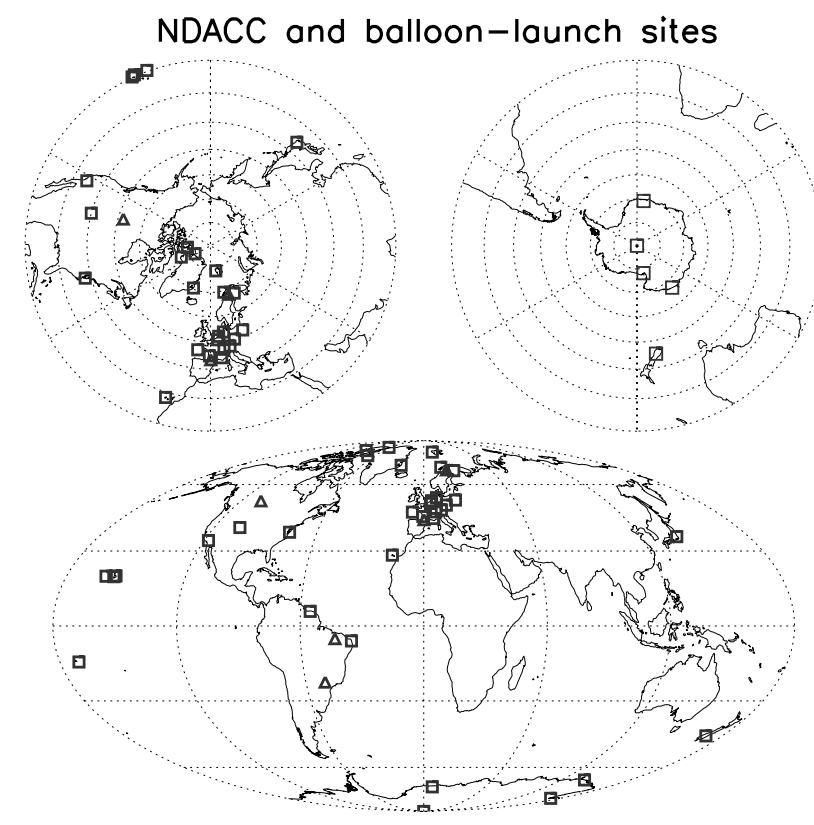

Fig. 6. NDACC sites (squares) and balloons launches (triangles) providing data for comparisons with Odin.

dars need clear nights for their measurements, but this has not been a relevant drawback for long-term monitoring.

Microwave radiometers record emission spectra from thermally induced rotational transitions of atmospheric ozone, typically around 110 or $142 \mathrm{GHz}$ (Parrish et al., 1992; Kämpfer, 1995; Connor et al., 1995; Schneider et al., 2003). Since the recorded transition lines are broadened by pressure, the recorded line shape contains information on the vertical distribution of ozone. A great advantage is that ground-based microwave radiometers are fairly independent of weather conditions and take measurements around the clock, with a typical time resolution of one or two hours. Altitude resolution and accuracy of the retrieved stratospheric ozone profiles are 7 to $10 \mathrm{~km}$ and 7 to $10 \%$, respectively. Many studies have validated ozone profiles from microwave radiometers (e.g., McDermid et al., 1998; McPeters et al., 1999; Tsou et al., 2000). More detailed descriptions of the Lidar and Microwave NDACC instruments are given by Steinbrecht et al. (2006).

\subsubsection{Comparisons}

We selected a first set of 23 stations where ozone sonde experiments are conducted from the surface to a maximum altitude in the range $33-38 \mathrm{~km}$. Figure 7 shows eight of these ozone sonde intercomparisons (Paramaribo, Natal, Boulder, Neumeyer, South Pole, Izana, Hilo). A second set of stations where lidar measurements are performed has been chosen to extend the validation up to the middle stratosphere. Microwave data were used to validate the Odin/SMR stratospheric measurements up to $60 \mathrm{~km}$. Figure 8 illustrates 

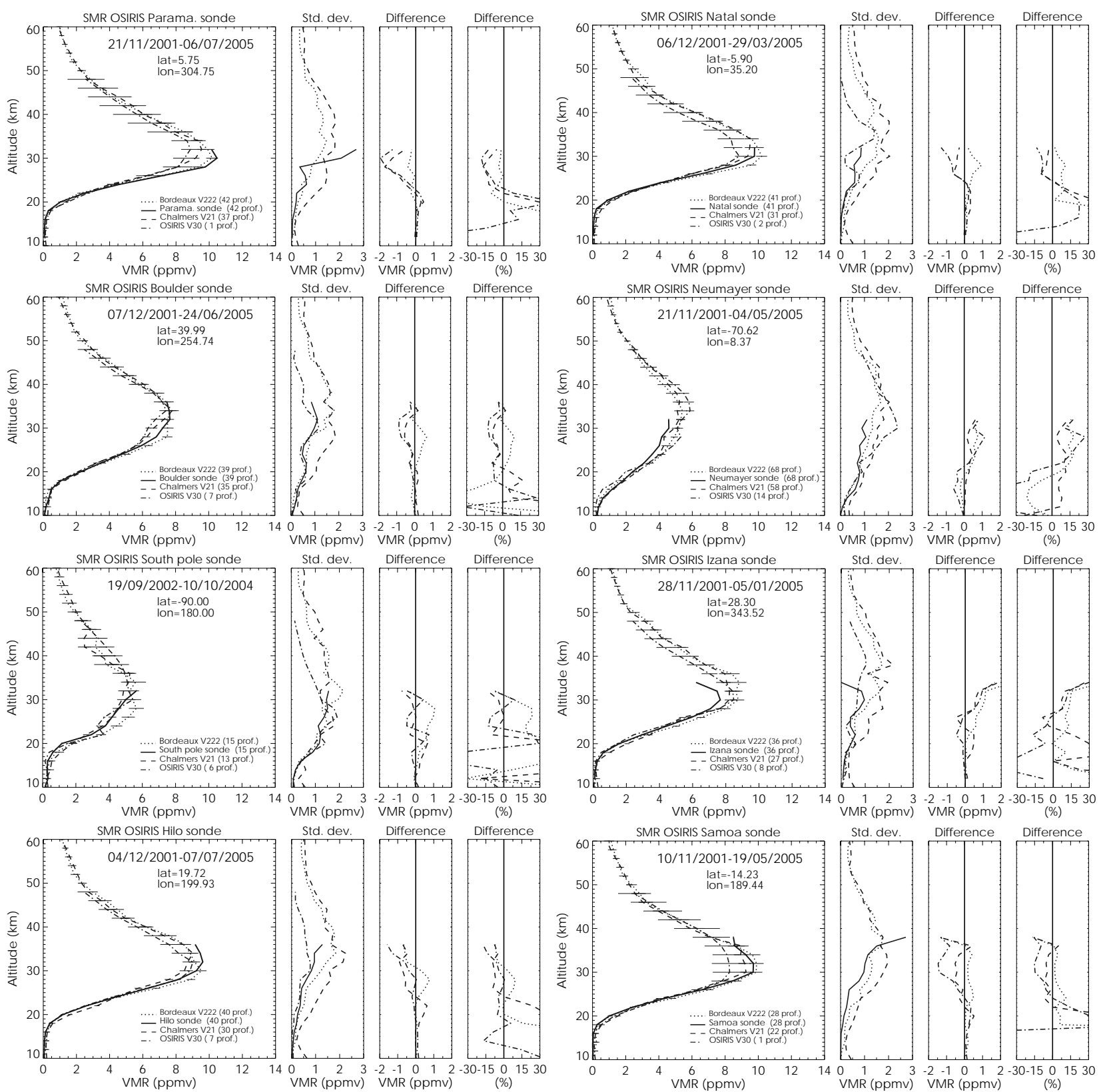

Fig. 7. Same as Fig. 3 but for monthly mean OSIRIS,SMR and ozone sonde profiles for eight NDACC stations: Paramaribo, Natal, Boulder, Neumeyer, South Pole, Izana, Hilo and Samoa Islands.

results from four lidar (Ny Alesund, Payerne, Bern, Lauder) and four microwave (Mauna Loa, Andoya, OHP, Tsukuba). NDACC and Odin data are compared over the whole available period for each station. Individual coincidences are found within the selected criteria. NDACC profiles are linearly interpolated as a function of log-pressure, to the fixed $\mathrm{SMR} / \mathrm{v} 222$ 2-km grid, before calculating the average profiles, shown on Figs. 7 and 8. Mean profiles are calculated taking into account the total error defined above. The number of profiles involved in the mean profiles is indicated on these figures.
The Odin/SMRv222 high bias below $10 \mathrm{hPa}(\sim 22-32 \mathrm{~km})$ is again found in most cases. On the contrary, the altitude offset of the Odin ozone maximum detected in the POAM III comparisons is not systematically found. Table 3 summarizes the Odin/NDACC intercomparison results for the selected stations shown in Figs. 7 and 8.

Figure 7 shows that SMR and OSIRIS profiles are in agreement with the ozone sonde data within $\pm 0.5 \mathrm{ppmv}$. The SMR/v222 and the SMR/v2.1 data agree within $0.2 \pm 0.3$ ppmv and $0 \pm 0.4$ ppmv below $35 \mathrm{~km}$, respectively. In general the SMR/v2.1 products reveal better agreement 

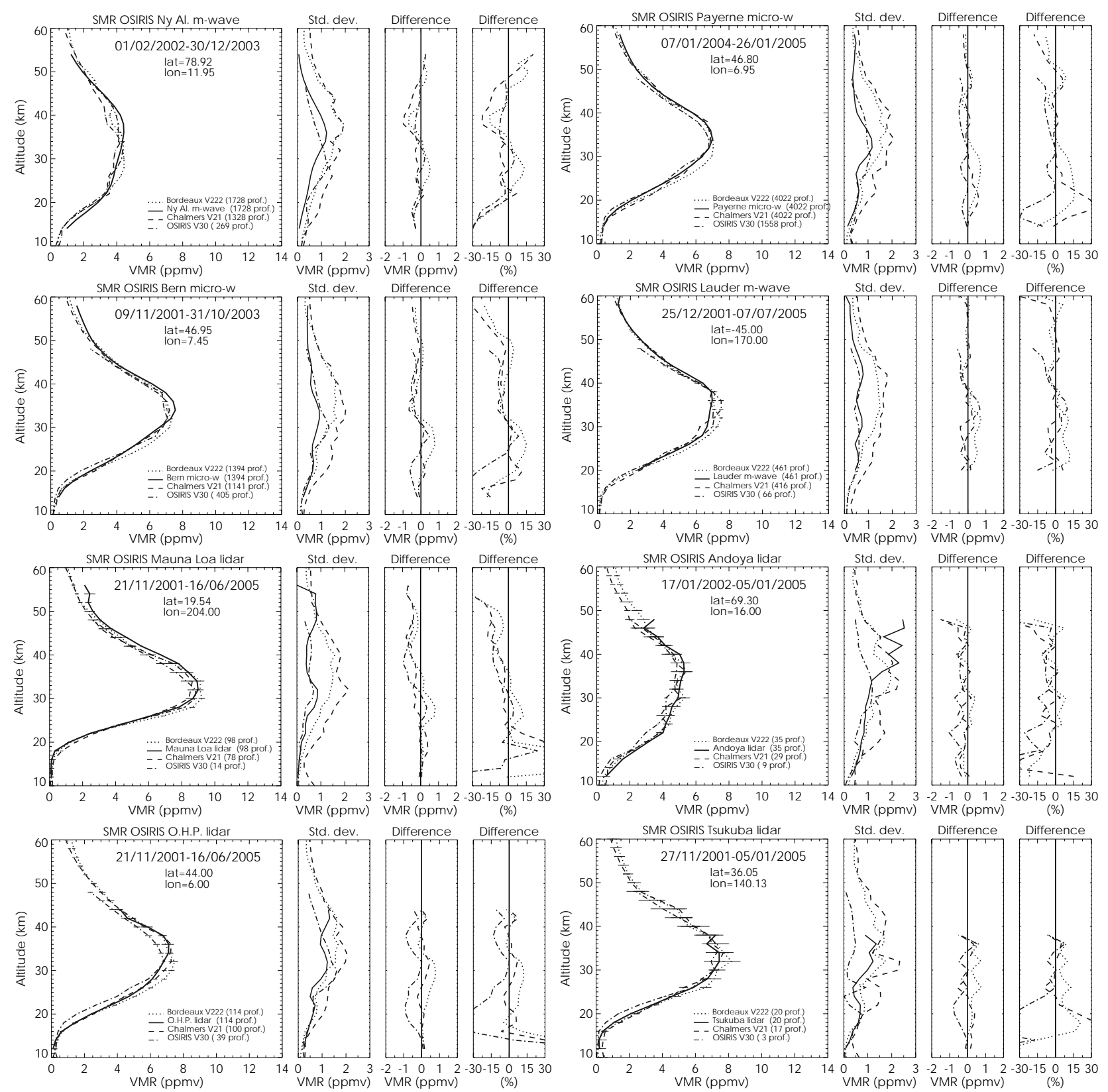

Fig. 8. Same as Fig. 7 but for comparisons of monthly mean OSIRIS,SMR and NDACC profiles performed in four microwave (Ny Alesund, Payerne, Bern, Lauder) and four lidar NAADC stations (OHP, Tsukuba, Mauna Loa, Andoya).

with the ozone sonde products than the other Odin products. Nevertheless in some cases the SMR/v222 data are the Odin products that are closest to the ozone sonde profiles. For example, the Paramaribo mean profile (cf. Fig. 7) shows the same SMR/v222 positive bias below $10 \mathrm{hPa}(\sim 32 \mathrm{~km}) \mathrm{com}-$ pared to the SMR/v2.1 data. The difference reaches $1.5 \mathrm{ppmv}$ around the ozone profile maximum near $30 \mathrm{~km}$. This altitude is $2 \mathrm{~km}$ higher in the SMR/v2.1 profiles. This new feature, also detected in the Odin/Samoa Islands comparisons (cf. Fig. 7), casts some doubt on the reality of the SMR/v222 positive bias below $10 \mathrm{hPa}(\sim 32 \mathrm{~km})$.
Figure 8 shows that Odin profiles are in agreement with the lidar and microwave sonde data within $0.3 \pm 0.3 \mathrm{ppmv} \quad$ (OSIRIS), $0.2 \pm 0.3 \mathrm{ppmv} \quad$ (SMR/v222), $-0.1 \pm 0.3 \mathrm{ppmv} \quad(\mathrm{SMR} / \mathrm{v} 2.1)$ for the $10-35 \mathrm{~km}$ range and within $-0.3 \pm 0.4 \mathrm{ppmv}$ (OSIRIS), $0 \pm 0.4 \mathrm{ppmv}$ $(\mathrm{SMR} / \mathrm{v} 222),-0.2 \pm 0.3 \mathrm{ppmv}(\mathrm{SMR} / \mathrm{v} 2.1)$ for the $35-$ $60 \mathrm{~km}$. The SMR/v222 positive bias below $10 \mathrm{hPa}(\sim 32 \mathrm{~km})$ is clearly seen in Fig. 8 in the low and middle latitude comparisons (Tsukuba, Mauna Loa, OHP, Bern, Lauder, Andoya) but not for the high-latitude stations (Ny Alesund, Andoya). This positive bias is systematically followed by 
Table 3. Comparisons of NDACC ground-based and Odin measurements for periods described in Table 2 for the microwave instruments (top), lidars (middle) and ozone sondes (bottom), respectively. Averages and standard deviations (number in brackets) of the absolute difference (Odin-NDACC (ppmv)) are given over the two height ranges 10-35 km and 35-60 km.

\begin{tabular}{|c|c|c|c|c|c|c|}
\hline \multicolumn{7}{|c|}{ NDACC sites } \\
\hline \multirow[t]{2}{*}{ Station } & \multicolumn{2}{|c|}{ v3.0-Station } & \multicolumn{2}{|c|}{ v222-Station } & \multicolumn{2}{|c|}{ v2.1-Station } \\
\hline & $10-35 \mathrm{~km}$ & $35-48 \mathrm{~km}$ & $10-35 \mathrm{~km}$ & $35-60 \mathrm{~km}$ & $10-35 \mathrm{~km}$ & $35-60 \mathrm{~km}$ \\
\hline \multicolumn{7}{|c|}{ Microwave instruments } \\
\hline Ny Alesund & $-0.18(0.34)$ & $-0.12(0.02)$ & $-0.06(0.25)$ & $-0.03(0.29)$ & $-0.41(0.21)$ & $-0.26(0.39)$ \\
\hline Payerne & $-0.06(0.21)$ & $-0.15(0.12)$ & $0.34(0.29)$ & $-0.06(0.15)$ & $0.19(0.24)$ & $-0.05(0.16)$ \\
\hline Bern & $-0.14(0.28)$ & $-0.32(0.13)$ & $0.20(0.41)$ & $-0.11(0.19)$ & $-0.02(0.27)$ & $-0.31(0.15)$ \\
\hline Lauder & $0.05(0.37)$ & $-0.26(0.40)$ & $0.41(0.24)$ & $-0.06(0.14)$ & $-0.05(0.26)$ & $-0.09(0.14)$ \\
\hline \multicolumn{7}{|c|}{ Lidars } \\
\hline Mauna Loa & $-0.07(0.26)$ & $-0.76(0.43)$ & $0.38(0.39)$ & $-0.21(0.26)$ & $-0.11(0.23)$ & $-0.33(0.22)$ \\
\hline Andoya & $-0.44(0.27)$ & $-0.24(0.53)$ & $-0.12(0.21)$ & $-0.13(0.35)$ & $-0.31(0.25)$ & $-0.49(0.47)$ \\
\hline O.H.P. & $-0.39(0.31)$ & $-0.35(0.18)$ & $0.30(0.28)$ & $0.02(0.14)$ & $0.13(0.18)$ & $0.11(0.22)$ \\
\hline Tsukuba & $-0.38(0.27)$ & $0.10(0.56)$ & $0.28(0.25)$ & $-0.03(0.69)$ & $0.08(0.25)$ & $0.08(0.36)$ \\
\hline \multicolumn{7}{|c|}{ Ozonesondes } \\
\hline Paramaribo & $-0.49(0.81)$ & & $-0.11(0.18)$ & & $-0.41(0.67)$ & \\
\hline Natal & $-0.26(0.52)$ & & $0.27(0.27)$ & & $-0.04(0.34)$ & \\
\hline Boulder & $-0.27(0.34)$ & & $0.11(0.25)$ & & $-0.09(0.28)$ & \\
\hline Neumeyer & $0.18(0.58)$ & & $0.28(0.38)$ & & $0.21(0.19)$ & \\
\hline South Pole & $-0.04(0.37)$ & & $0.36(0.44)$ & & $-0.01(0.37)$ & \\
\hline Izana & $0.22(0.63)$ & & $0.60(0.76)$ & & $0.37(0.56)$ & \\
\hline Hilo & $-0.21(0.38)$ & & $0.08(0.35)$ & & $-0.11(0.47)$ & \\
\hline Samoa & $-0.33(0.64)$ & & $0.19(0.16)$ & & $-0.08(0.33)$ & \\
\hline
\end{tabular}

an altitude offset around the ozone peak. The SMR/v222 ozone maximum is lower by about $1-5 \mathrm{~km}$ compared to the lidar and microwave measurements. In the $35-60 \mathrm{~km}$ altitude range lidar and microwave observations are in good agreement with the Odin products with no latitudinal dependence.

We combine the results obtained from the comparisons with the NDACC data in Fig. 9. Mean and standard deviations are again calculated for the three range of the ozone mixing ratio. At low ozone mixing ratios (range $0-3 \mathrm{ppmv}$ ), we find differences of $0.1 \pm 0.15 \mathrm{ppmv}$ and $0.15 \pm 0.25$ for SMR v222 and v2.1, while OSIRIS v3.0 shows a negative difference of $-0.25 \pm 0.2$. Standard deviations are in order of 0.6-1.2 ppmv, 0.8-1.0 ppmv, 0.50.7 ppmv, for SMR v222, SMR v2.1 and OSIRIS v3.0, respectively. For the intermediate range (range 3-6 ppmv) differences of $0.2 \pm 0.1 \mathrm{ppmv}, \pm 0.15 \mathrm{ppmv},-0.15 \pm 0.15 \mathrm{ppmv}$, and standard deviations of 1.1-1.3 ppmv, 1.4-1.5 ppmv, and 0.9-1.0 ppmv, for SMR v222, SMR v2.1 and OSIRIS v3.0, respectively. At high ozone mixing ratios (69 ppmv), the corresponding differences are $-0.1 \pm 0.1 \mathrm{ppmv}$, $-0.5 \pm 0.2 \mathrm{ppmv}$, and $-0.45 \pm 0.2 \mathrm{ppmv}$, and standard deviations of $1.4-1.7 \mathrm{ppmv}, 1.7-1.9 \mathrm{ppmv}$, and $0.9-1.2 \mathrm{ppmv}$. A curious feature that looks like the thumb on a mitten appears on the OSIRIS/ozonesonde and OSIRIS/microwave scatterplots. There is a concentration of OSIRIS values at about 4 ppmv while corresponding ozonesonde and microwave values vary up to $7 \mathrm{ppmv}$. This discrepancy is the consequence of the low quality of the maximum altitude values of several NDACC measurements. This feature is not detected in the SMR/NDACC scatterplot because of the large oscillations in the individual SMR profiles.

In summary, the NDACC/Odin comparisons confirm that a positive bias exists most of the time in the SMR/v222 data between 22 and $32 \mathrm{~km}(0.2 \pm 0.3 \mathrm{ppmv})$. Such an overestimation cannot be generalised because this discrepancy completely disappears at some latitudes (tropical and Northern high latitude stations). The negative bias of the OSIRIS profiles is still found $(-0.3 \pm 0.3 \mathrm{ppmv})$ at all altitudes. This discrepancy is more important in the middle atmosphere $(z \geq 40 \mathrm{~km})$ where ozone values are lower. The SMR/v2.1 profiles are the Odin products showing the best agreement with the NDACC dataset $(-0.15 \pm 0.3$ ppmv) over all altitudes because neither an ozone altitude peak offset nor an amplitude difference were detected. 

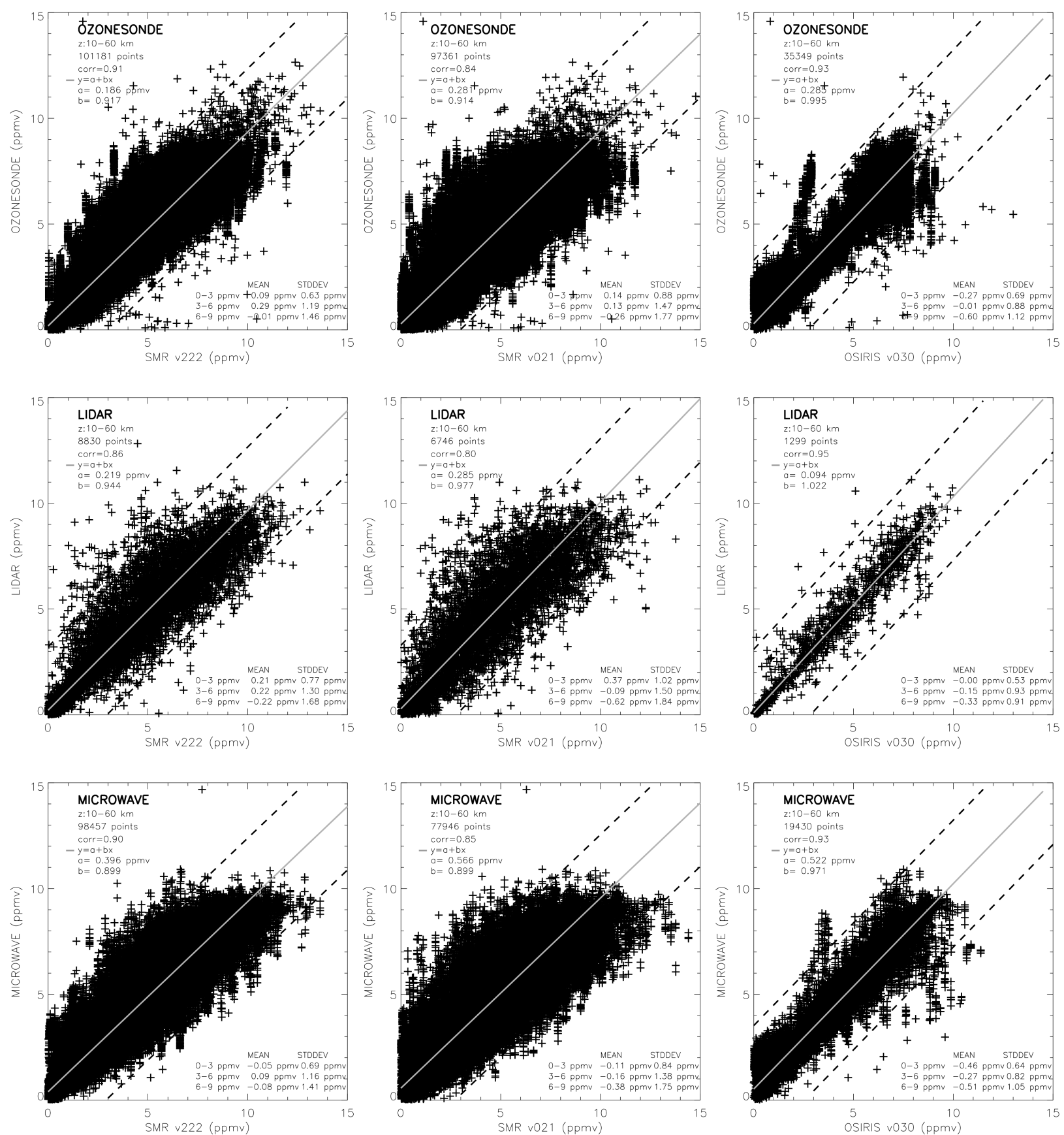

Fig. 9. Scatterplot of Odin/SMR and OSIRIS $\mathrm{O}_{3}$ versus NDACC measurements. Left: Odin/SMR v222 data; middle: Odin/SMR v2.1 data; right: Odin/OSIRIS v3.0 data. Top: Ozonesonde, Middle: Lidar, Bottom: Micro-wave. Mean differences and standard deviations are indicated for the different ranges of the $\mathrm{O}_{3}$ mixing ratio. The dotted lines delimit deviations of \pm 3 ppmv for clarity. The solid gray line indicates the linear fit to the data. 
Table 4. Comparisons of balloon flight and Odin measurements for periods described in Table 2 for the LPCE (top), MANTRA (middle) and SAOZ (bottom) missions, respectively. Averages and standard deviations (number in brackets) of the absolute difference (Odin-balloon (ppmv)) are given over the two height ranges 10$35 \mathrm{~km}$ and $35-60 \mathrm{~km}$.

\begin{tabular}{|c|c|c|c|}
\hline \multicolumn{4}{|c|}{ Balloons flights } \\
\hline Date & $\begin{array}{r}\text { v3.0-Balloon } \\
10-35 \mathrm{~km}\end{array}$ & $\begin{array}{r}\text { v222-Balloon } \\
10-35 \mathrm{~km}\end{array}$ & $\begin{array}{r}\text { v2.1-Balloon } \\
10-35 \mathrm{~km}\end{array}$ \\
\hline \multicolumn{4}{|c|}{ LPCE missions } \\
\hline SALOMON 2002 & $-0.19(0.56)$ & $0.80(1.04)$ & $0.77(1.02)$ \\
\hline SPIRALE 2002 & $0.25(1.29)$ & $0.03(1.09)$ & $0.14(1.01)$ \\
\hline SPIRALE 2003 & & $0.23(1.05)$ & $0.27(0.98)$ \\
\hline AMON 2003 & & $-0.58(0.59)$ & $0.04(1.00)$ \\
\hline SPIRALE 2005 & $-0.10(0.48)$ & & $-0.05(1.90)$ \\
\hline SPIRALE 2006 & & & $-0.26(1.25)$ \\
\hline \multicolumn{4}{|c|}{2002 MANTRA missions } \\
\hline $15 / 08$ & & $-0.21(1.07)$ & $0.30(1.20)$ \\
\hline $24 / 08$ & & $-0.14(0.45)$ & $-0.10(1.15)$ \\
\hline $17 / 08$ & $-0.35(0.35)$ & & $-0.34(1.45)$ \\
\hline $27 / 08$ & & & $-0.03(1.00)$ \\
\hline $02 / 09$ & & $0.08(1.33)$ & $-0.03(0.98)$ \\
\hline $15 / 08-02 / 09$ & & $-0.02(0.77)$ & $-0.13(0.75)$ \\
\hline \multicolumn{4}{|c|}{ SAOZ missions } \\
\hline $18 / 02 / 2003$ & & $0.65(0.69)$ & $0.69(1.42)$ \\
\hline $31 / 01 / 2004$ & & $0.70(0.65)$ & $0.38(0.97)$ \\
\hline
\end{tabular}

\subsection{Large balloon-borne experiments}

Correlative measurements by balloon-borne sensors are available from experiments conducted by the LPCE (AMON, SALOMON, SPIRALE instrument flights), by the Canadian Space Agency (MANTRA flights) and by the Service d'Aéronomie (SAOZ instrument flights). The obtained profiles have a high vertical resolution compared to that of individual SMR/Odin profiles. Furthermore high noise is present in individual SMR profiles due to measurement noise (Figs. 10, 11 and 12). However these balloon-borne measurements are the opportunity to investigate the accuracy of the individual Odin/SMR profiles. Table 4 summarizes the Odin/balloon-borne instrument intercomparison results for the LPCE, MANTRA, and SAOZ missions.

AMON (French acronym for Absorption par les Minoritaires Ozone et Nox) and SALOMON (French acronym for Spectroscopie d'Absorption Lunaire pour l'Observation des Minoritaires Ozone et Nox) are two UV-visible spectrometers used aboard stratospheric balloons (Renard et al.,1996, 2000, 2007). These experiments measure $\mathrm{O}_{3}, \mathrm{NO}_{2}, \mathrm{NO}_{3}$, and $\mathrm{OClO}$ vertical profiles and aerosol extinction coefficients, between 15 and $40 \mathrm{~km}$. A balloon carrying the SALOMON spectrometer was launched on 19 September 2002 from Aire sur 1'Adour (Southern France). High-latitude flight of the balloon-borne AMON instrument was performed on 1 March 2003 starting from Kiruna (Northern Sweden) at the edge of the polar vortex. The AMON observations have a vertical resolution between a few hundred meters in the middle stratosphere and around $1 \mathrm{~km}$ in the lower stratosphere. Accuracy of the AMON ozone measurements is better than 5\%. Due to the apparent size of the Moon $\left(0.5^{\circ}\right)$ SALOMON does not allow a vertical resolution better than $1-2 \mathrm{~km}$ (Berthet et al., 2003). Accuracy of the SALOMON ozone measurements is $6-14 \%$. These flights were planned within the validation campaign for the ENVISAT satellite. These measurements are shown in Fig. 10a, b along with ozone data from Odin/SMR and OSIRIS. The time coincidences are $7 \mathrm{~h}$ for the AMON/Odin and $4 \mathrm{~h}$ for the SALOMON/Odin intercomparisons. The spatial coincidence criteria are $\leq 5^{\circ}$ in latitude and $\leq 10^{\circ}$ in longitude.

The AMON profile Fig. 10a and the Odin/SMR measurements are in a good agreement from 11 to $31 \mathrm{~km}$ within \pm 1.0 ppmv. The SMR and AMON profiles show the same features: a decrease between $22-23 \mathrm{~km}$ and $27-28 \mathrm{~km}$ followed by an increase at the upper altitude $(29-31 \mathrm{~km})$. Polar Stratospheric Clouds (PSC) detected during this experiment, could explain the ozone decrease in the $22-23 \mathrm{~km}$ altitude range.

The SMR profiles show rapid variations of concentration in altitude but in general the amplitude of these changes is larger than these observed in the balloon profiles. The AMON upper altitude is $2 \mathrm{~km}$ lower than the SMR maximum ozone peak. The SALOMON and Odin/SMR comparison does not exhibit such a good agreement as seen in Fig. 10b. The agreement is within $0.8 \pm 1$ ppmv with two different altitude features. The SALOMON profiles are systematically greater $(\leq 0.5 \mathrm{ppmv})$ from 16 to $22 \mathrm{~km}$ and lower $(\leq 1.5 \mathrm{ppmv})$ from 22 to $36 \mathrm{~km}$. OSIRIS profiles are lower within $0.2 \pm 0.6 \mathrm{ppmv}$ in the $22-32 \mathrm{~km}$ altitude range. The SALOMON profile is located between SMR and OSIRIS profiles from $15-32 \mathrm{~km}$ with SMR lower than SALOMON from $15-22 \mathrm{~km}$ and OSIRIS lower than SALOMON from $22-32 \mathrm{~km}$. The SALOMON profile is lower than that of the Odin products between 32 and $39 \mathrm{~km}$, without going out of the SMR error bars. In the $32-39 \mathrm{~km}$ altitude range the low values $(0.5-1 \mathrm{ppmv})$ of the OSIRIS profile from 22 to $32 \mathrm{~km}$ show a better agreement with the SALOMON profile ( \pm 0.5 ppmv).

SPIRALE (French acronym for SPectroscopie InfraRouge par Absorption de Lasers Embarqués) is a tunable diode laser spectrometer used to measure chemical trace species from the high troposphere up to middle stratosphere (35 km) (Berthet al., 2006, Huret et al., 2006). Vertical concentration profiles of twelve species $\left(\mathrm{O}_{3}, \mathrm{CH}_{4}, \mathrm{CO}, \mathrm{CO}_{2}\right.$, $\mathrm{N}_{2} \mathrm{O}, \mathrm{HNO}_{3}, \mathrm{NO}_{2}, \mathrm{NO}, \mathrm{HCl}, \mathrm{HOCl}, \mathrm{H}_{2} \mathrm{O}_{2}, \mathrm{CO}_{2}$ ) were measured with a high vertical resolution $(\leq 5 \mathrm{~m})$. Accuracy of the ozone measurements is 3-5\%. Four SPIRALE instrument flights occurred from 2002 to 2006: two in Kiruna, Sweden (21 January 2003, 20 January 2006), one in Aire sur l'Adour, France (2 October 2002), and one in Teresina, Brasil (22 June 2005). 

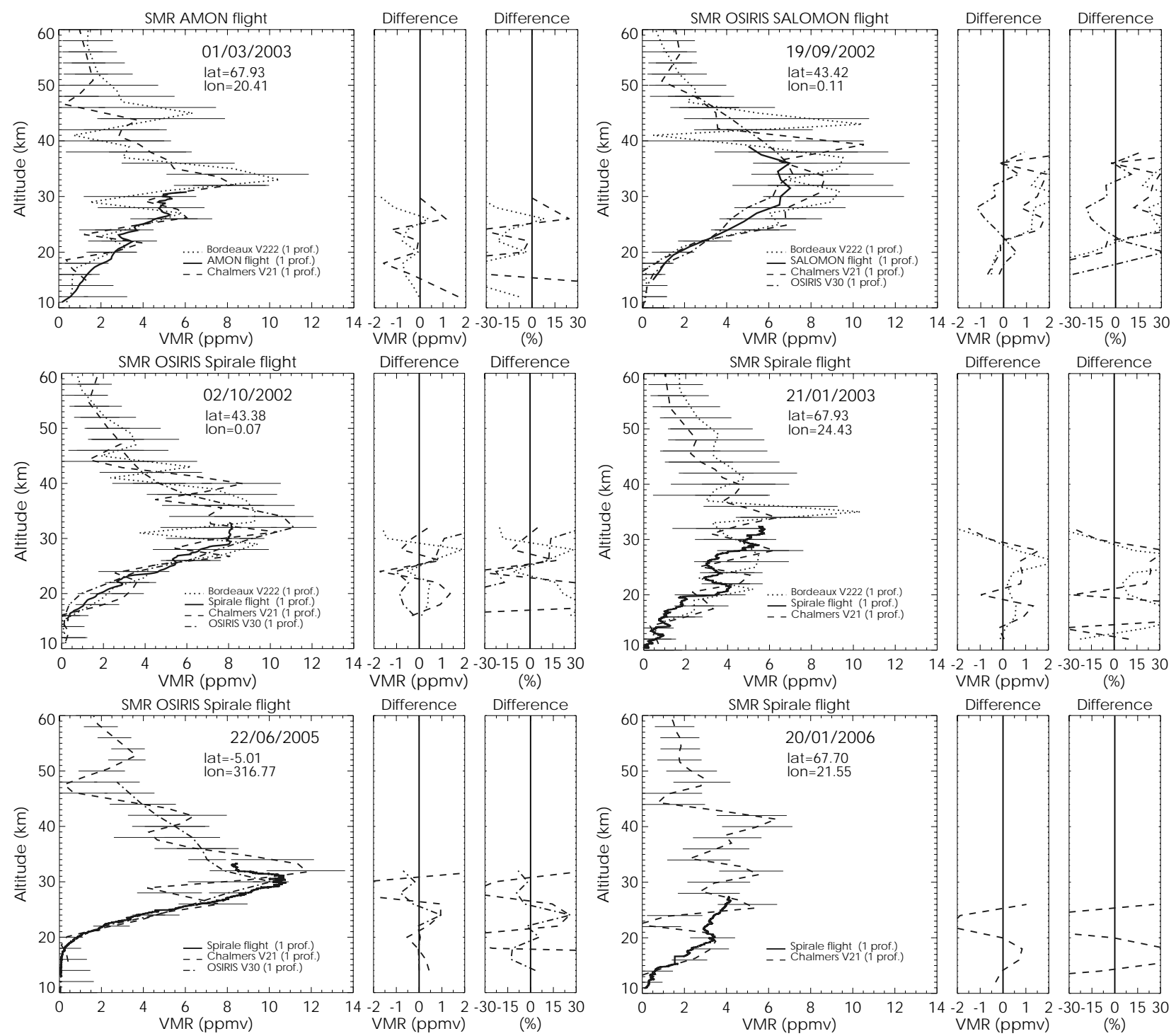

Fig. 10. Same as Fig. 8 but for comparisons of OSIRIS,SMR ozone with measurements of the balloon-borne AMON (a), SALOMON (b), SPIRALE (c, d, e, f) instruments measured during flights performed between 19 September 2002 and 22 June 2006.

Figure 10c shows the comparison of Odin/SMR and OSIRIS measurements of ozone with mid-latitude observations of the balloon-borne SPIRALE instrument performed on 2 October 2002 in Aire sur l'Adour, France. The temporal coincidence is $5 \mathrm{~h}$ and the spatial coincidences are $\leq 5^{\circ}$ in latitude and $\leq 10^{\circ}$ in longitude. The SPIRALE profile is characterised by a constant increase from 18 to $29 \mathrm{~km}$ with two slight amplitude inversions at 22 and $27 \mathrm{~km}$. This complex vertical structure has been already highlighted during the Odin $\mathrm{N}_{2} \mathrm{O}$ validation (Urban et al., 2005). A $\mathrm{CH}_{4}$ $\mathrm{N}_{2} \mathrm{O}$ correlation has been used to investigate the origin of air masses. A more detailed study on air mass origin, using the same tracer correlations, have been made by Huret et al. (2006). Different origins were found for air masses measured at low altitudes and high altitudes. At the top of the profile a maximum ozone value of 8 ppmv spread over $4 \mathrm{~km}$ $(29-33 \mathrm{~km})$. We find a reasonable average agreement with OSIRIS $(0.25 \pm 1.3 \mathrm{ppmv}), \mathrm{SMR} / \mathrm{v} 222(0.03 \pm 1.1 \mathrm{ppmv})$ and $\mathrm{SMR} / \mathrm{v} 2.1(0.14 \pm 1.0 \mathrm{ppmv})$ profiles from $16 \mathrm{~km}$ to $32 \mathrm{~km}$. The Odin profiles in this case do not detect the two inversions at 22 and $28 \mathrm{~km}$ and show a maximum ozone peak 2$3 \mathrm{~km}$ higher in altitude.

Figure 10d shows the comparison of Odin/SMR measurement of ozone with a SPIRALE profile obtained on 21 January 2003 in Kiruna (Sweden) near the edge of the polar vortex. The temporal coincidence is $10 \mathrm{~h}$ and the spatial coincidences are $\leq 5^{\circ}$ in latitude and $\leq 10^{\circ}$ in longitude. In view of the complex structure of the SPIRALE profile, we investigate the location of the observations in relation to the polar vortex. To achieve this, we use a simulation of potential 
vorticity obtained with the MIMOSA model (Hauchecorne et al., 2002) developed at the Service d'Aéronomie (France), which reproduces the dynamics of the vortex situation during the SPIRALE flight. Odin profiles are found near the inside edge of the polar vortex. The SPIRALE profile is outside the polar vortex below $23 \mathrm{~km}$ and inside the polar vortex above. This point could be the explanation of the relative high difference between SPIRALE and Odin profiles below $23 \mathrm{~km}$. The SPIRALE profile structure is divided in two parts: a first part with low values increasing from 0-2 ppmv in the 10$20 \mathrm{~km}$ altitude range and a second part above $20 \mathrm{~km}$ with a very sudden increase of the order of 2 ppmv over only $2 \mathrm{~km}$. This ozone doubling corresponds to the change of the dynamic regime. The $22-33 \mathrm{~km}$ altitude range is characterised by two roughly constant ozone regions respectively of the order of $3.5 \mathrm{ppmv}(22-27 \mathrm{~km})$ and $5.4 \mathrm{ppmv}(29-32 \mathrm{~km})$ which surround a second sudden increase. The SMR profiles are greater than the SPIRALE profile except near the two ozone maxima ( $\sim 21$ and $29 \mathrm{~km})$. The average agreement is within $0.25 \pm 1.0 \mathrm{ppmv}$ for both SMR versions.

Figure 10e shows the comparison of SMR measurement of ozone with a SPIRALE profile obtained on 22 June 2005 in Teresina (Brasil). The temporal coincidence has been released to $72 \mathrm{~h}$ to find some available coincidences. The spatial coincidences are $\leq 5^{\circ}$ in latitude and $\leq 10^{\circ}$ in longitude. We found two Odin dates, 19 and 24 June 2005, when comparisons could be performed. We note that good agreement occurs only with the 19 June Odin profile. We conclude that a change in air mass characteristics occurred a few days after the SPIRALE observation. The SPIRALE profile has an expected structure with extremely low values from 10 to $18 \mathrm{~km}$ with a rapid and monotonic increase from 18 to $29 \mathrm{~km}$. The $10.5 \mathrm{ppmv}$ ozone peak maximum at $30 \mathrm{~km}$ is followed by a quick decrease down to $8.2 \mathrm{ppmv}$ at $33 \mathrm{~km}$. Odin profiles show slightly lower values within $0.05 \pm 1.9 \mathrm{ppmv}$ for SMR/v2.1 and $0.10 \pm 0.5 \mathrm{ppmv}$ for OSIRIS. The OSIRIS ozone maximum altitude corresponds to the SPIRALE one with an amplitude slightly $0.7 \mathrm{ppmv}$ lower. The SMR/v2.1 ozone maximum is located $2 \mathrm{~km}$ higher with a greater amplitude of 1 ppmv. In this case the Odin/OSIRIS product has the best agreement with the SPIRALE profile.

Figure 10f shows the comparison of a SMR measurement of $\mathrm{O}_{3}$ with a SPIRALE profile obtained on 20 January 2006 in Kiruna (Sweden). The SPIRALE profile does not exhibit the large variations detected in the Kiruna 2003 profile. Nevertheless two features characterise this profile: a constant amplitude from 14 to $17 \mathrm{~km}$ and two successive inversions at 20 and $22 \mathrm{~km}$. The agreement is quite good from 10 to $20 \mathrm{~km}$ whereas the SMR/v2.1 profile shows large oscillations (noise) up to $60 \mathrm{~km}$. The average agreement is within $0.25 \pm 1.25$ ppmv. Figure $10 \mathrm{f}$ is a good example of the limitation of individual comparisons due to oscillations in SMR profiles.
The MANTRA (Middle Atmosphere Nitrogen TRend Assessment) series of high-altitude balloon flights has been undertaken to investigate changes in the concentration of mid-latitude stratospheric ozone, nitrogen and chlorine compounds which play a role in the ozone chemistry. Four campaigns have been undertaken since August 1998, all from Vanscoy, Saskatchewan, Canada $\left(52^{\circ} \mathrm{N}, 107^{\circ} \mathrm{W}\right)$. Each flight carried a payload of instruments to measure vertical concentration profiles of stratospheric trace gases, and made observations from a float altitude of about $35 \mathrm{~km}$ during one day. The third MANTRA flight was launched on 3 September 2002 and measurements were made by 11 instruments. In addition, four ground-based spectrometers were deployed at Vanscoy approximatively two weeks prior to this flight between 15 August and 5 September, and a total of 15 independent Electrochemical Concentration Cell (ECC) ozone sonde flights were launched. The ECC sonde measurement technique is based on the reaction of ozone with the potassium iodine in an aqueous solution to yield molecular iodine. The iodine is detected via electrochemical means, and is directly related to the ozone abundance (Komhyr et al., 1969; Davis et al., 2000). Typically, the ozone partial pressure is measured at $50-100 \mathrm{~m}$ vertical resolution with an accuracy of $\pm 10 \%$. For more details about the MANTRA 2002 balloon flight from Vanscoy, see Strong et al. (2003, 2005). Five ozone sonde profiles, on 15, 17, 24, 27 August and 2 September 2002 are within our 24-h time comparison criterion. The spatial coincidences are $\leq 5^{\circ}$ in latitude and $\leq 10^{\circ}$ in longitude. Figure 11a shows mean ozone profiles measured on 15-17 August 2002 and 2 September 2002 when both SMR/v222 and SMR/v2.1 coincidences are found. In this mean comparison (Fig. 11a), we find an excellent agreement from 12 to $36 \mathrm{~km}$ within $0.15 \pm 0.8 \mathrm{ppmv}$. We observe a positive bias of SMR/v222 between 24 and $32 \mathrm{~km}$ and a negative bias of SMR/v2.1 between 20 and $30 \mathrm{~km}$, reversed below $20 \mathrm{~km}$. Overall, for Fig. 11a, the mean MANTRA profile is situated between both versions of SMR profiles within the SMR error bar. The SMR and MANTRA ozone maximum peaks are very similar with the same altitude $(34 \mathrm{~km})$ and amplitude (7.8 ppmv).

The five individual comparisons (Fig. 11b, c, d, e, f) do not show such a good agreement for two reasons: (1) individual SMR profiles are characterised by large oscillations which are reduced in the mean profiles, (2) the individual ozone sonde profiles show some fine structures that are smoothed in the mean profiles. An inversion is detected near $25 \mathrm{~km}$ in the MANTRA profiles while it is not detected in the SMR observations due to limited altitude resolution and measurement noise. Nevertheless the regular ozone increase is similar in all individual MANTRA and Odin profiles from 10 to $38 \mathrm{~km}$ and the average agreement is $-0.1 \pm 0.9 \mathrm{ppmv}$ for SMR/v222, within $\pm 0.8 \mathrm{ppmv}$ for SMR/v2.1 and OSIRIS. No discrepancy is found in the altitude and amplitude of the ozone maximum peak. We find that the altitude of the maximum ozone is between 33 and $34 \mathrm{~km}$ with an amplitude 

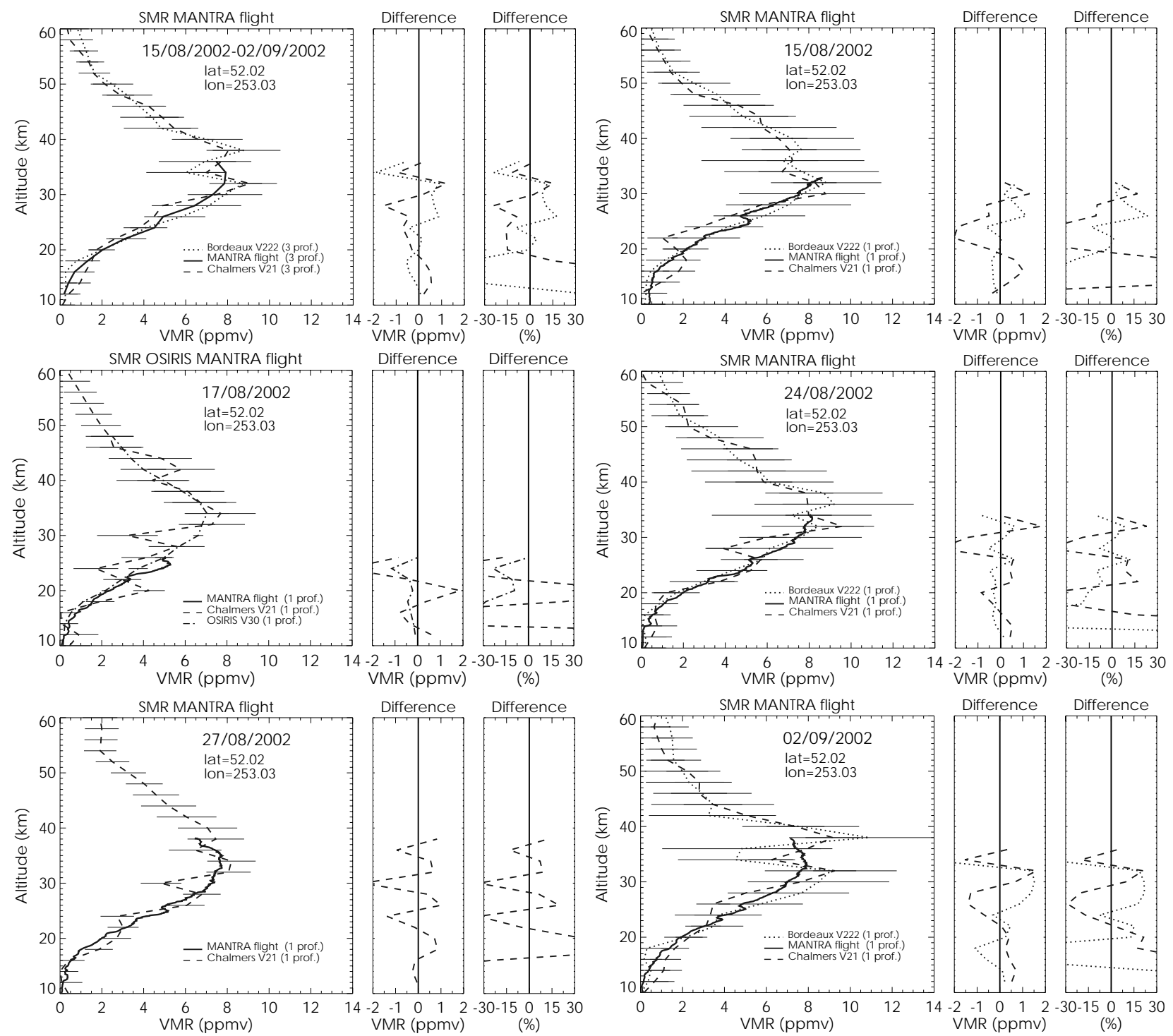

Fig. 11. Same as Fig. 10 but for comparisons of OSIRIS and SMR ozone with measurements of the balloon-borne MANTRA instrument measured during flights performed between 15 August 2002 and 2 September 2002. Figure (a) shows the average profiles over the period 15 August-2 September when the two SMR versions are presented.

within 7.8-8.5 ppmv. Odin products detect a surprising low ozone maximum of the order of $7 \mathrm{ppmv}$ at $34 \mathrm{~km}$ on $17 \mathrm{Au}-$ gust 2002. Unfortunately the MANTRA profile upper altitude $(26 \mathrm{~km})$ on 17 August 2002, does not give the opportunity to validate the sudden ozone decrease. But Odin and sonde ozone peaks match well on other days, which suggests a real rapid ozone decrease on 17 August 2002. A persistent minimum at $30 \mathrm{~km}$ in v2.1 data is found from 17 August 2002 to 2 September 2002. The origin of this minimum is not clearly explained and could probably be noise.

SAOZ (French acronym for Systeme d'Analyse et d'Observation Zénithales) is a balloon-borne diode array UV-visible spectrometer for remote ozone and $\mathrm{NO}_{2}$ observations by solar occultation (Pommereau and Piquard, 1994).
The precision of the measurements is estimated to be better than 2\% (3.5\% accuracy) in the stratosphere and 5-6\% (12\% and $25 \%$ accuracy at $15 \mathrm{~km}$ and $10 \mathrm{~km}$ respectively) in the troposphere with an altitude uncertainty of $-30 \pm 25 \mathrm{~m}$ (Borchi et al.,2005). The data used here are those obtained by two flights launched from Bauru at $22^{\circ} \mathrm{S}$ in Brasil during the SH summer season in January-February 2003 and 2004. The first flight on 18 February 2003 was launched in preparation for the HIBISCUS campaign (Borchi et al., 2007), and the second one on 31 January 2004 was launched during the main campaign. The first flight was performed at sunrise $(20 \mathrm{~km}$ tangent height at 09:00) $4 \mathrm{~h}$ ahead SMR, whilst the second was at sunset $(20 \mathrm{~km}$ tangent height at 22:00), 09:20 after SMR. SAOZ profiles are characterised 

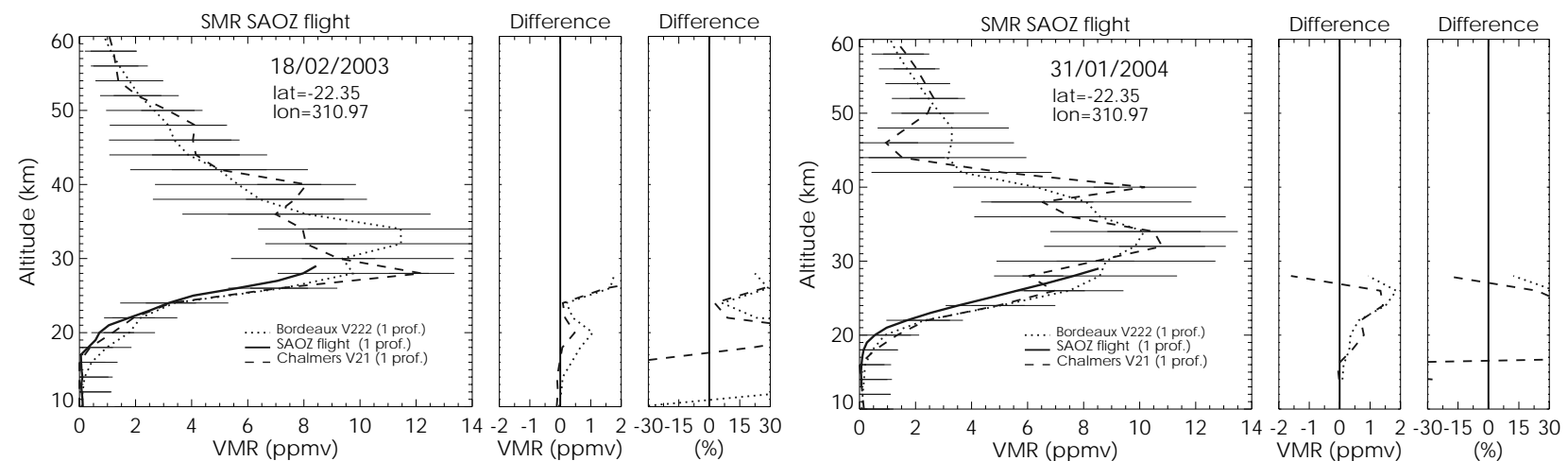

Fig. 12. Same as Fig. 11 but for comparisons of Odin/SMR ozone with measurements of the balloon-borne SAOZ instrument measured during flights launched in Bauru (Brasil) o*n 18 February 2003 the morning (a) and 31 January 2004 the evening (b).
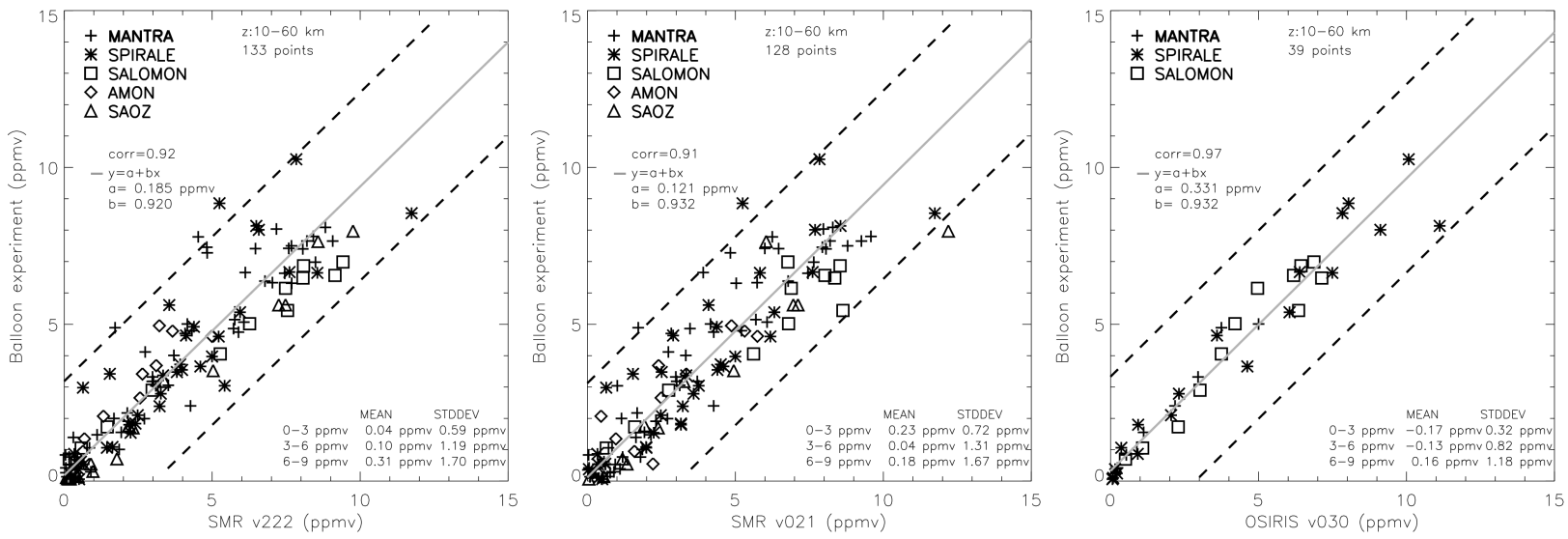

Fig. 13. Scatterplot of Odin/SMR and OSIRIS $\mathrm{O}_{3}$ versus Balloon measurements. Left: Odin/SMR v222 data; middle: Odin/SMR v2.1 data; right: Odin/OSIRIS v3.0 data. Mean differences and standard deviations are indicated for the different ranges of the $\mathrm{O}_{3}$ mixing ratio. The dotted lines delimit deviations of \pm 3 ppmv for clarity. The solid gray line indicates the linear fit to the data.

by a regular increase from 10 to $29 \mathrm{~km}$ with a maximum ozone amplitude of 8.5-9 ppmv. Reasonable agreement is found between SMR and SAOZ profiles $0.7 \pm 0.7 \mathrm{ppmv}$ for v222 and $0.6 \pm 1.2$ ppmv for v2.1. The SMR profiles systematically overestimate the SAOZ observations except the $\mathrm{SMR} / \mathrm{v} 2.12004$ profile in the upper $3 \mathrm{~km}$. In spite of this feature, SAOZ values are always within the SMR error bars (cf. Fig. 12a, b).

Finally, the differences between Odin products and Balloon-borne experiments are estimated quantitatively. Figure 13 combines all the results obtained from the balloon comparisons from August 2002 to January 2006. For low mixing ratios of ozone (range $0-3$ ppmv), we find differences within $0.05 \pm 0.6 \mathrm{ppmv}, 0.2 \pm 0.7 \mathrm{ppmv}$, and $-0.2 \pm 0.3 \mathrm{ppmv}$, for SMR v222, SMR v2.1 and OSIRIS v3.0, respectively. In the intermediate range (3-6 ppmv), the deviations are $0.1 \pm 1.2$ ppmv, $0.05 \pm 1.3$ ppmv, for SMR version 222 and 2.1 and $-0.15 \pm 0.8$ ppmv for OSIRIS v3.0. High ozone mixing ratios (range 6-9 ppmv) show differences of $0.3 \pm 1.7 \mathrm{ppmv}$, $0.2 \pm 1.7 \mathrm{ppmv}$, and $0.15 \pm 1.2 \mathrm{ppmv}$, for version SMR 222, SMR 2.1 and OSIRIS 3.0.
In summary, the balloon/Odin comparisons prove that individual SMR profiles show reasonable agreement with high vertical resolution profiles. In some cases rapid ozone variations are simultaneously detected in SMR and balloon profiles. Balloon profiles are always within the SMR error bar. Average agreements over the available altitude ranges are within $\pm 1 \mathrm{ppmv}$ for AMON, $0.8 \pm 1 \mathrm{ppmv}$ for SALOMON, $0.25 \pm 1.3$ ppmv for SPIRALE, $0.15 \pm 0.8$ ppmv for MANTRA and $0.6 \pm 1.2$ ppmv for SAOZ instruments.

\section{Summary and conclusions}

The Sub-Millimeter-Radiometer on board the Odin satellite, launched in February 2001, provides a quasi-continuous global dataset of stratospheric ozone profiles starting in November 2001. We present an assessment of the quality of the latest level 2 data version (Chalmers SMR/v2.1) of the $501.8 \mathrm{GHz}$ band product with correlative measurements performed by ground-based, balloon-borne and space-borne sensors. Odin/SMR retrievals are in good agreement with ozone mixing ratios obtained by the POAM III v4.0 level 
2 off-line processor. The cross-comparison shows a negative bias of the Odin/SMR and OSIRIS ozone measurements compared to the POAM III v4.0 data. For SMR versions 2.1 and v222, standard deviation of the (Odin-POAM III) differences are within $1.3 \mathrm{ppmv}$ and the agreement is better than 0.3 ppmv. OSIRIS v3.0 shows a standard deviation of the (Odin-POAM III) difference within $0.9 \mathrm{ppmv}$ and an agreement better than 0.5 ppmv. SMR v222 profiles are found to be higher $(\leq 10 \%)$ than POAM III mixing ratios below $10 \mathrm{hPa}$ $(\sim 32 \mathrm{~km})$. This positive bias has already been highlighted by Barret et al. (2006) in SMR/MLS intercomparisons. The Odin ozone maximum peak is lower than that of POAM III $\sim 1-3 \mathrm{~km}$ (OSIRIS) and $\sim 1-5 \mathrm{~km}$ (SMR).

An agreement with the NDACC experiments is found within $0.5 \mathrm{ppmv}$ for all Odin data. A positive bias at pressures below $10 \mathrm{hPa}(\sim 32 \mathrm{~km})$ is found in SMR v222 data. This positive bias is mainly detected in tropical and Northern high latitudes. OSIRIS data are smaller than NDACC measurements with a $-0.3 \pm 0.3$ ppmv bias. SMR v2.1 data are in general in agreement within $-0.15 \pm 0.3$ ppmv.

The cross-comparison with large balloon-borne instruments at Southern tropical and Northern middle and high latitudes shows a good agreement of the order of $0.7 \pm 1 \mathrm{ppmv}$ for all Odin products. The individual profile comparisons show large oscillations. Averaging of SMR profiles reduces such oscillations. With average SMR profiles comparisons show that fine structures can be investigated by looking for the origin of air masses.

In general, no discrepancy has been detected in SMR v2.1 data indicating ranges of altitude (or latitude) with wrong ozone amounts compared with POAM III, NDACC and large balloon-borne instruments measurements. In the SMR v2.1 data, no different systematic error has been found in the 0 $35 \mathrm{~km}$ range in comparison with the $35-60 \mathrm{~km}$ range. The same feature has been highlighted in both hemispheres in SMR v2.1/POAM III intercomparisons, and no latitudinal dependence has been revealed in SMR v2.1/NDACC intercomparisons.

In conclusion, we can describe the status of the SMR ozone level 2 data products by evaluating the quality of both presently available data versions: Chalmers v2.1 and CTSO v222. Version 2.1, the most recent and advanced version, appears to be better according to this validation study. Chalmers SMR v2.1 data have the advantage of avoiding an overestimation in the $20-30 \mathrm{~km}$ altitude range and to be processed over the whole Odin measurement period. The CTSO SMR v222 data have been processed through July 2005 and have been validated in Barret et al. (2006). SMR version v222 profiles show better agreement compared to the SMR v2.1 data only in some cases, e.g., in the tropical regions. We recommend therefore to use the Chalmers SMR v2.1 data.

In general, only good quality SMR profiles (assigned flag QUALITY $=0$ ) should be used for scientific studies and the measurement response associated with each retrieval should be larger than 0.75 , to ensure that the information comes pri- marily from measurements and not from the contribution of the climatological a priori profiles used by the OEM retrieval. Improvements are still in progress in Sweden to obtain a convergent version of the SMR ozone level 2 data. In the future, the Odin/SMR ozone multi-year climatology, based on operational v2.1 data, will provide a useful dataset for the climate modelling community to validate their simulations and to improve our understanding of the climate system.

Acknowledgements. We thank University of Saskatchewan Odin/OSIRIS group for their early works on the OSIRIS validation; the POAM III team, the MANTRA 2002 science team (supported by the Canadian Space Agency (CSA), Environment Canada, the Natural Sciences and Engineering Research Council of Canada (NSERC), and the Service d'Aéronomie), the LPCE and Service d'Aéronomie for making ozone data freely available. Data used in this publication was obtained as part of the Network for the Detection of Atmospheric Composition Change (NDACC) and is publicly available (see http://www.ndacc.org). The authors wish to thank C. Boonne and F. Girod of the French database "Ether" for their assistance to the validation effort. This work was supported by the Centre National d'Etudes Spatiales (CNES). Odin is a Swedish-led satellite project funded jointly by Sweden (SNSB), Canada (CSA), France (CNES) and Finland (Tekes) and is since 2007 supported by the European Space Agency (ESA).The OSIRIS ozone retrievals and validation have been supported by the Canadian Space Agency and the Natural Science and Engineering Research Council, Canada.

Edited by: G. Roberts

\section{References}

Barath, F. T., Chavez, M. C., Cofield, R. E., Flower, D. A., Frerking, M. A., Gram, M. B., Harris, W. M., Holden, J. R., Jarnot, R. F., and Kloezeman, W. G.: The Upper Atmosphere Research Satellite Microwave Limb Sounder Instrument, J. Geophys. Res., 98, 10751-10762, 1993.

Barret, B., Ricaud, P., Santee, M.L., Attié, J.L., Urban, J., Le Flochmoën, E., Berthet, G., Murtagh, D.,Eriksson, P., Jones, A., de La Noë, J., Dupuy, E., Froidevaux, L., Livesey, N.J., Waters, J. W., and Filipiak, M. J.: Intercomparisons of trace gases profiles from the Odin/SMR and Aura/MLS limb sounders, J. Geophys. Res., 111, D21302, doi:10.1029/2006JD007305, 2006.

Baron, P., Ricaud, P, de La Noë, J., Eriksson, J. E., Merino, F., Ridal, M., and Murtagh, D. P.: Studies for the Odin sub-millimetre radiometer. II. Retrieval methodology, Can. J. Phys., 80(4), 341356, 2002.

Bertaux, J. L., Mégie, G., Widemann, T., Chassefière, E., Pellinen, R., Kyrola, E., Korpela, S., and Simon, P.: Monitoring of Ozone Trend by Stellar Occultation: The GOMOS Instrument, Adv. Space Res., 11, 3237-3242, 1991.

Berthet, G., Renard, J. B., Chartier, M., Pirre M., and Robert C.: Analysis of $\mathrm{OBrO}, \mathrm{IO}$, and $\mathrm{OIO}$ absorption signature in UVvisible spectra measured at night and at sunrise by stratospheric balloon-borne instruments, J. Geophys. Res., 108(D5), 4161, doi:10.1029/2002JD002284, 2003. 
Berthet, G., Huret, N., Lefèvre, F., Moreau, G., Robert, C., Chartier, M., Catoire, V., Barret, B., Pisso, I., and Pomathiod, L.: On the ability of chemical transport models to simulate the vertical structure of the $\mathrm{N} 2 \mathrm{O}, \mathrm{NO} 2$ and $\mathrm{HNO} 3$ species in the mid-latitude stratosphere, Atmos. Chem. Phys., 6, 1599-1609, 2006,

http://www.atmos-chem-phys.net/6/1599/2006/.

Bovensmann, H., Burrows, J. P., Buchwitz, M., Frerick, J., Noël, S., Rozanov, V. V., Chance, K. V., and Goede, A. P. H.: SCIAMACHY - Mission Objectives and Measurement Modes, J. Atmos. Sci., 56, 127-150, 1999.

Borchi, F., Pommereau, J. P., Garnier A., and Pinharanda, M.: Evaluation of SHADOZ sondes, HALOE and SAGE II ozone profiles at the tropics from SAOZ UV-Vis remote measurements onboard long duration balloons, Atmos. Chem. Phys., 5, 13811397, 2005,

http://www.atmos-chem-phys.net/5/1381/2005/.

Borchi, F. and Pommereau, J. P.: Evaluation of ozonesondes, HALOE, SAGE II and III, Odin-OSIRIS and SMR, and ENVISAT-GOMOS, -SCIAMACHY and -MIPAS ozone profiles in the tropics from SAOZ long duration balloon measurements in 2003 and 2004, Atmos. Chem. Phys., 7, 2671-2690, 2007, http://www.atmos-chem-phys.net/7/2671/2007/.

Brohede, S., Jones, A., and Jégou F.: Internal consistency in the Odin stratospheric ozone products, Can. J. Phys., 85(11), 12751285, 2007.

Buehler, S. A., Eriksson, P, Kuhn, T, von Engeln, A and Verdes, C: ARTS, the atmospheric radiative transfer simulatior, J. Quant. Spectros. Radiat. Transfer, 91, 65-93, 2005.

Burrows, J. P., Buchwitz, M., Eisinger, M., Rozanov, V., Weber, M., Richter, A., and Ladstaetter-Weissenmayer, A.: The Global Ozone Monitoring Experiment (GOME): Mission Concept and First Scientific Results, J. Atmos. Sci., 56, 151-175, 1999.

Connor, B. J., Parrish, A., Tsou, J. J., and McCormick, M. P.: Error analysis for the ground-based microwave ozone measurements during STOIC, J. Geophys. Res., 100, 9283-9291, 1995.

Davies, J., Tarasick, D., McElroy, C. T., Kerr, J. B., Fogal, P. F. and Savastiouk, V.: Evaluation of ECC Ozonesonde Preparation Methods from Laboratory Tests and Field Comparisons using MANTRA, Proc. Quadrennial Ozone Symposium, Sapporo, Japan, 2000.

De Clercq, C., Gerard, P., Granville, J., Lambert, J.C., and the ACVT-GBMCD Ozone Profile Team: Geophysical consistency of Envisat ozone profile data with global atmosphere watch poleto-pole network measurements, Proceedings of the third workshop on the atmospheric chemistry validation of Envisat, Italy, 4-7 December 2006, ESA SP-642, February 2007.

Degenstein, D. A., Llewellyn, E. J., and Lloyd, N. D.: Volume Emission Rate Tomography from a Satellite Platform, Appl. Optics, 42, 1441-1450, 2002.

Eriksson, P., Ekström, M., Melsheimer, C., and Buehler, S.: Efficient forward modelling by matrix representation of sensor responses, Int. J. Remote Sens., 27(9), 1793-1808, 2006.

Flittner, D. E., Bhartia, P. K., and Herman, B. M.: $\mathrm{O}_{3}$ profiles retrieved from limb scatter measurements: Theory, Geophys. Res. Lett., 27, 2601-2604, 2000.

Frisk, U., Hagstrm, M., Ala-Laurinaho, J., Andersson, S., Berges, J. C., Chabaud, J. P., Dahlgren, M., Emrich, A., Florén, H. G., Florin, G., Fredrixon, M., Gaier, T., Haas, R., Hirvonen, T., Hjalmarsson, A., Jakobsson, B., Jukkala, P., Kildal, P. S., Kollberg,
E., Lassing, J., Lecacheux, A., Lehikoinen, P., Lehto, A., Mallat, J., Marty, C., Michet, D., Narbonne, J., Nexon, M., Olberg, M., Olofsson, A. O. H., Olofsson, G., Origné, A., Petersson, M., Piironen, P., Pons, R., Pouliquen, D., Ristorcelli, I., Rosolen, C., Rouaix, G., Räisänen, A.V., Serra, G., Sjöberg, F., Stenmark, L., Torchinsky, S., Tuovinen, J., Ullberg, C., Vinterhav, E., Wadefalk, N., Zirath, H., Zimmermann, P., and Zimmermann, R.: The Odin Satellite: I. Radiometer Design and Test, Astron. Astrophys., 402, 27-34, 2003.

Glaccum, W. J., Lucke, R. L., Bevilacqua, R. M., Shettle, E. P., Hornstein, J. S., Chen, D. T., Lumpe, J. D., Krigman, S. S., Debrestian, D., Fromm, M. D., Dalaudier, F., Chassefière, E., Deniel, C., Randall, C. E., Rusch, D. W., Oliviero, J. J., Brogniez, C., Lenoble, J. and Kremer, R.: The Polar Ozone and Aerosol Measurement (POAM II) Instrument, J. Geophys. Res., 101, 14 479-14 487, 1996.

Godin, S., Carswell, A. I., Donovan, D. P., Claude, H., Steinbrecht, W., McDermid, I. S., McGee, T. J., Gross, M. R., Nakane, H., Swart, D. P. J., Bergwerff, H. B., Uchino, O., von der Gathen, P., and Neuber, R.: Differential Absorption Ozone Lidar Algorithm Intercomparison, Appl. Optics, 38, 6225-6236, 1999.

Haley, C. S. and S. M. Brohede: Status of the Odin/OSIRIS stratospheric $\mathrm{O}_{3}$ and $\mathrm{NO}_{2}$ data products, Can. J. Phys., 85(11), 11771194, 2007.

Hartmann, G. K., Bevilacqua, R. M., Schwartz, P. R., Kämpfer, N., Künzi, K. F., Aellig, C. P., Berg, A., Boogaerts, W., Connor, B. J., Croskey, C. L., Daehler, M., Degenhardt, W., Dicken, H. D., Goldizen, D., Kriebel, D., Langen, J., Loidl, A., Olivero, J. J., Pauls, T. A., Puliafito, S. E., Richards, M. L., Rudin, C., Tsou, J. J., Waltman, W. B., Umlauft, G., and Zwick, R.: Measurements of $\mathrm{O}_{3}, \mathrm{H}_{2} \mathrm{O}$ and $\mathrm{ClO}$ in the Middle Atmosphere using the Millimeter-Wave Atmospheric Sounder (MAS), Geophys. Res. Lett., 23, 2313-2316, 1996.

Hauchecorne, A., Godin, S., Marchand, M., Heese, B., and Souprayen, C.: Quantification of the transport of chemical constituents from the polar vortex to midlatitudes in the lower stratosphere using the highresolution advection model MIMOSA and effective diffusivity, J. Geophys. Res., 107(D20), 8289, doi:10.1029/2001JD000491, 2002.

Heath, D. E., Krueger, A. J., Roeder, H. R., and Henderson, B. D.: The Solar Backscatter Ultraviolet and Total Ozone Mapping Spectrometer (SBUV/TOMS) for Nimbus 7, Opt. Eng., 14, 323331, 1975.

Huret, N., Pirre, M., Hauchecorne, A., Robert, C., and Catoire, V.: On the vertical structure of the stratosphere at midlatitudes during the first stage of the polar vortex formation and in the polar region in the presence of a large mesospheric descent, J. Geophys. Res., 111, D06111, doi:10.1029/2005JD006102, 2006.

Jin, J. J., Semeniuk, K., Jonsson, A. I., Beagley, S. R., McConnell, J. C., Boone, C. D., Walker, K. A., Bernath, P. F., Rinsland, C. P., Dupuy, E., Ricaud, P., De La Noë, J., Urban, J., and Murtagh, D.: Severe Arctic ozone loss in the winter 2004/2005: observations from ACE-FTS, Geophys. Res. Lett., 33, L15801, doi:10.1029/2006GL026752, 2006.

Jones, A., Murtagh, D., Urban, J., Eriksson, P., and Rösevall, J.: Intercomparison of Odin/SMR ozone measurements with MIPAS and balloon sonde data, Can. J. Phys., 85(11), 1111-1123, 2007.

Kämpfer, N.: Microwave remote sensing of the atmosphere in Switzerland, Opt. Eng., 34, 2413-2424, 1995. 
Keckhut, P., McDermid, S., Swart, D., McGee, T., GodinBeekmann, S., Adriani, A., Barnes, J., Baray, J. L., Bencherif, B., Claude, H., di Sarra, A. G., Fiocco, G., Hansen, G., Hauchecorne, A., Leblanc, T., Lee, C. H., Pal, S., Megie, M., Nakane, H., Neuber, R., Steinbrecht W., and Thayer, J.:Review of ozone and temperature lidar validations performed within the framework of the Network for the Detection of Stratospheric Change, J. Environ. Monitor., 6, 721-733, doi:10.1039/b404256e, 2004.

Komhyr, W. D.: Electrochemical concentration cells for gas analysis, Ann. Geophys., 25, 203-210, 1969,

http://www.ann-geophys.net/25/203/1969/.

Kuttippurath, J., Bremer, H., Burrows, J., Kleinböhl, A., Küllmann, H., Künzi, K., Notholt, J., Sinnhuber, M., von Savigny, C., Lautiè, N., Murtagh, D., Urban, J., Milz, M., Stiller, G., Petelina, S. V., de La Noë, J., Le Flochmoën, E, and Ricaud, P.: Intercomparison of ozone profile measurements from ASUR, SCIAMACHY, MIPAS, OSIRIS, and SMR, J. Geophys. Res., 112, D09311, doi:10.1029/2006JD007830, 2007.

Llewellyn, E. J., Degenstein, D. A., Lloyd, N. D., Gattinger, R. L., Petelina, S. V., McDade, I.C., Haley, C. S., Solheim, B. H., von Savigny, C., Sioris, C., Evans, W. F. J., Strong, K., Murtagh, D. P., and Stegman J.: First Results from the OSIRIS Instrument onboard Odin, Sodankylä Geophysical Observatory Publications, 92, 41-47, 2003.

Llewellyn, E. J., Lloyd, N. D., Degenstein, D. A., Gattinger, R. L., Petelina, S. V., Bourassa, A. E., Wiensz, J. T., Ivanov, E. V., McDade, I. C., Solheim, B. H., McConnell, J. C., Haley, C. S., von Savigny, C., Sioris, C. E., McLinden, C. A., Griffioen, E., Kaminski, J., Evans, W. F. J., Puckrin, E., Strong, K., Wehrle, V., Hum, R. H., Kendall, D. J. W., Matsushita, J., Murtagh, D. P., Brohede, S., Stegman, J., Witt, G., Barnes, G., Payne, W. F., Pich, L., Smith, K., Warshaw, G., Deslauniers, D. L., Marchand, P., Richardson, E. H., King, R. A., Wevers, I., McCreath, W., Kyrölä, E., Oikarinen, L., Leppelmeier, G. W., Auvinen, H., Mégie, G., Hauchecorne, A., Lefèvre, F., de La Noë, J., Ricaud, P., Frisk, U., Sjoberg, F., von Schéele, F., and Nordh, L.: The OSIRIS Instrument on the Odin Spacecraft, Can. J. Phys, Volume 82, Number 6, 411-422(12), 2004.

Lucke, R. L., Korwan, D. R., Bevilacqua, R. M., Hornstein, J. S., Shettle, E. P., Chen, D. T., Daehler, M., Lumpe, J. D., Fromm, M. D., Debrestian, D., Neff, B., Squire, M., König-Langlo, G., and Davies, J.: The Polar Ozone and Aerosol Measurements (POAM III) Instrument and Early Validation Results, J. Geophys. Res., 104, 18 785-18 799, 1999.

Lumpe, J. D., Bevilacqua, R. M., Hoppel, K. W., and Randall, C. E.: POAM III retrieval algorithm and error analysis, J. Geophys. Res., 107(D21), 4575, doi:10.1029/2002JD002137, 2002.

Lumpe, J. D., Bevilacqua, R. M., Randall, C. E., Nedoluha, G., Hoppel, K. W., Russell, J., Harvey, V. L., Schiller, C., Sen, B., Taha, G., Toon, G., and Vömel, H.: Validation of Polar Ozone and Aerosol Measurement (POAM) III version 4 stratospheric water vapor, J. Geophys. Res., 111, D11301, doi:10.1029/2005JD006763., 2006.

McCormick, M. P., Zawodny, J. M., Veiga, R. E., Larsen, J. C., and Wang, P. H.: An Overview of SAGE I and II Ozone Measurements, Planet. Space Sci., 37(12), 1567-1586, 1989.

McCormick, M. P., Chu, W. P., Zawodny, J. M., Mauldin, L. E., and McMaster, L. R.: Stratospheric Aerosol and Gas Experiment
III (SAGE III) Aerosol and trace gas measurements from Earth Observing System (EOS), Symp. Aerospace Sensing, Int. Soc. Opt. Eng., 1491-1516, 1991.

McDermid, I. S., Bergwerff, J. B., Bodeker, G., Boyd, I. S., Brinksma, E. J., Connor, B. J., Farmer, R., Gross, M. R., Kimvilakani, P., Matthews, W. A., McGee, T. J., Ormel, F. T., Parrish, A., Singh, U., Swart, D. P. J., and Tsou, J. J.: OPAL: Network for the detection of stratospheric change ozone profiler assessment at Lauder, New Zealand. II. Intercomparison of revised results, J. Geophys. Res., 103, 28 693-28 700, 1998.

McLinden, C. A., Fioletov, V. E., Haley, C. S., Lloyd, N., Roth, C., Degenstein, D., Bourassa, A., McElroy, C. T., and Llewellyn, E. J.: An evaluation of Odin/OSIRIS limb pointing and stratospheric ozone through comparisons with ozonesondes, Can. J. Phys., 85, 1125-1141, 2007.

McPeters, R. D., Hofmann, D. J., Clark, M., Flynn, L., Froidevaux, L., Gross, M., Johnson, B., Koenig, G., Liu, X., McDermid, S., McGee, T., Murcray, F., Newchurch, M. J., Oltmans, S., Parrish, A., Schnell, R., Singh, U., Tsou, J. J., Walsh, T., and Zawodny, J. M.: Results from the 1995 stratospheric ozone profile intercomparison at Mauna Loa, J. Geophys. Res., 104, 30 505-30 514, 1999.

McPeters, R. D., Janz, S. J., Hilsenrath, E., Brown, T. L., Flittner, D. E., Heath, D. F.: The Retrieval of O3 profiles from Limb Scatter Measurements: Results from the Shuttle Ozone Limb Sounding Experiment, Geophys. Res. Lett., 27, 2597-2600, 2000.

Merino, F., Murtagh, D. P., Baron, P., Ricaud, P., de La Noë, J., and Eriksson, P.: Studies for the Odin Sub-Millimeter Radiometer: I. Radiative transfer and instrument simulation, Can. J. Phys., 80(4), 321-340, 2002.

Merino, F., Murtagh, D. P., Baron, P., Ricaud, P., de La Noë, J., and Eriksson, P.: Studies for the Odin Sub-Millimeter Radiometer: III. Performance simulations, Can. J. Phys., 80(4), 357-373, 2002.

Murtagh, D. P., Frisk, U., Merino, F., Ridal, M., Jonsson, A., Stegman, J., Witt, G., Eriksson, P., Jimenez, C., Mégie, G., de La Noë, J., Ricaud, P., Baron, P., Pardo, L. R., Hauchecorne, A., Llewellyn, E. J., Degenstein, D. A., Gattinger, R. L., Lloyd, N. D., J. Evans, W. F., McDade, I. C., Haley, C., Sioris, C., von Savigny, C., Solheim, G. H., McConnell, J. C., Strong, K., Richardson, E. H., Leppelmeier, G. W., Kyrölä, E., Auvinen, H., and Oikarinen, L.: An Overview of the Odin Atmospheric Mission, Can. J. Phys., 80(4), 309-319, 2002.

Nakajima, H., Suzuki, M., Matsuzaki, A., Ishigaki, T., Waragai, K., Mogi, Y., Kimura, N., Araki, N., Yokota, T., Kanzawa, H., Sugita, T., and Sasano, Y: Characteristics and performance of the Improved Limb Atmospheric Spectrometer (ILAS) in orbit, J. Geophys. Res., 107(D24), 8213, 10.1029/2001JD001439, 2002.

Olberg, M., Frisk, U., Lecacheux, A., Olofsson, A. O. H., Baron, P., Bergman, P., Florin, G., Hjalmarson, A., Larsson, B., Murtagh, D. P., Olofsson, G., Pagani, L., Sandqvist, A., Teyssier, D., Torchinsky, S. A., and Volk, K.: The Odin satellite: II. Radiometer data processing and calibration, Astron. Astrophys., 402(3), 35-38, 2003.

Parrish, A., Connor, B. J., Tsou, J. J., McDermid, I. S., and Chu, W. P.: Ground-based microwave monitoring of stratospheric ozone, J. Geophys. Res., 97, 2541-2546, 1992.

Pelon, J. and Mégie, G.: Ozone monitoring in the troposphere and lower stratosphere: Evaluation and operation of a ground-based 
lidar station, J. Geophys. Res., 87, 4947-4955, 1982.

Petelina, S. V., Llewellyn, E. J., Degenstein, D. A., Lloyd, N. D., Gattinger, R. L., Haley, C. S., von Savigny, C., Griffioen, E., McDade, I. C., Evans, W. F. J., Murtagh, D. P., and de La Noë, J.: Comparison of the Odin/OSIRIS stratospheric ozone profiles with coincident POAM III and ozonesonde measurements, Geophys. Res. Lett., 31, L07105, doi:1029/2003GL019299, 2004.

Petelina, S. V., Llewellyn, E. J., Walker, K. A., Degenstein, D. A., Boone, C. D., Bernath, P. F., Haley, C. S., von Savigny, C., Lloyd, N. D., and Gattinger, R. L.: Validation of ACE-FTS stratospheric ozone profiles against Odin/OSIRIS measurements, Geophys. Res. Lett., 32, L15S06, doi:10.1029/2005GL02237, 2005.

Pommereau, J. P. and Piquard, J.: Ozone, Nitrogen dioxide and Aerosol vertical distributions by UV-visible solar occultation from balloons, Geophys. Res. Lett., 21, 1227-1230, 1994.

Randall, C. E., Rusch, D. W., Bevilacqua, R. M., Hoppel, K. W., Lumpe, J. D., Shettle, E., Thompson, E., Deaver, L., Zawodny, J., Kyrö, E., Johnson, B., Kelder, H., Dorokhov, V. M., KönigLanglo, G., and Gil, M.: Validation of POAM III ozone: Comparisons with ozonesonde and satellite data, J. Geophys. Res., 108(D12), 4367, doi:10.1029/2002JD002944, 2003.

Renard, J. B., Pirre, M., Robert, C., Huguenin, D., Moreau, G., and Russell, J. M.: Nocturnal distribution of stratospheric $\mathrm{O}_{3}$, $\mathrm{NO}_{2}$, and $\mathrm{NO}_{3}$ from balloon measurements, J. Geophys. Res., 101(D22), 28 793-28 804, 1996.

Renard, J. B., Chartier, Robert, C., Chalumeau, G., Berthet G., Pirre, M., Pommereau J. P., and Goutail F.: SALOMON: a new light balloon-borne UV visible spectrometer for night-time observations of stratospheric trace gas species, Appl. Optics, 39, 3, 386-392, 2000.

Renard, J. B., Berthet, B., Brogniez, C., Catoire, V., Fussen, D., Goutail, F., Oelhaf, H., Pommereau, J. P., Roscoe, H., Wetzel, G., Chartier, C., Robert, C., Balois, J. Y., Verwaerde, C., Auriol, F., François, F., Gaubicher, B., and Wursteisen P.: Validation of GOMOS-ENVISAT vertical profiles of $\mathrm{O}_{3}, \mathrm{NO}_{2}, \mathrm{NO}_{3}$, and aerosol extinction using balloon-borne instruments, J. Geophys. Res., 113, A02302, doi:10.1029/2007JA012345, 2008.

Roche, A. E., Kumer, J. B., Mergenthaler, J. L., Ely, G. A., Uplinger, W. G., Potter, J. F., James, T. C., and Sterritt, L. W.: The Cryogenic Limb Array Etalon Spectrometer CLAES on UARS: Experiment Description and Performance, J. Geophys. Res., 98, 10763-10775, 1993.

Rodgers, C.D.: Retrieval of Atmospheric Temperature and Composition from Remote Measurements of Thermal Radiation, Rev. Geophys. Space Phys., 14, 609-624, 1976.

Rusch, D.W., Mount, G. H., Barth, C. A., Thomas, R. J., and Callan, M. T.: Solar Mesospheric Explorer Ultraviolet Spectrometer : Measurements of Ozone in the 1.0-0.1 mbar region, J. Geophys. Res., 89, 11 677-11689, 1984.

Russell, J. M. III, Gordley, L. L., Park, J. H., Drayson, S. R., Hesketh, D. H., Cicerone, R. J., Tuck, A. F., Frederick, J. E., Harries, J. E., and Crutzen, P.: The halogen occultation experiment, J. Geophys. Res., 98, 10777-10 797, 1993.

Schneider, N., Lezeaux, O., de La Noë, J, Urban, J., and Ricaud, R.: Validation of ground-based observations of stratomesospheric ozone, J. Geophys. Res., 108(D17), 4540, doi:10.1029/2002JD002925, 2003.

Seftor, C.J., Larsen, J. C., Remund, Q., Rodriguez, J. V., Flynn, L. E. and Hilsenrath, E.: The ozone mapping and profiler suite: Ex- tending the BUV technique to meet future ozone measurement requirements, Eos Trans. AGU, 84(46), Fall Meet. Suppl., Abstract A21D-1010, 2003.

Sioris, C.E., Haley, C. S., McLinden, C. A., von Savigny, C., McDade, I. C., McConnell, J. C., Evans, W. F. J., Lloyd, N. D., Llewellyn, E. J., Chance, K. V., Kurosu, T. P., Murtagh, D., Frisk, U., Pfeilsticker, K., Bösch, H., Weidner, F., Strong, S., Stegman, J., and Mégie, G.: Stratospheric Profiles of Nitrogen Dioxide Observed by Optical Spectrograph and Infrared Imager System on the Odin Satellite, J. Geophys. Res., 108(D7), 4215, doi:10.1029/2002JD002672, 2003.

Steinbrecht, W., Claude, H., Schönenborn, F., McDermid, I. S., Leblanc, T., Godin, S., Song, T., Swart, D. P. J., Meijer, Y. J., Bodeker, G. E., Connor, B. J., Kämpfer, N., Hocke, K., Calisesi, Y., Schneider, N., de la Noë, J., Parrish, A. D., Boyd, I. S., Brühl, C., Steil, B., Giorgetta, M. A., Manzini, E., Thomason, L. W., Zawodny, J. M., McCormick, M. P., Russell III, J. M., Bhartia, P. K., Stolarski, R. S., and Hollandsworth-Frith, S. M.: Long-term evolution of upper stratospheric ozone at selected stations of the Network for the Detection of Stratospheric Change (NDSC), J. Geophys. Res., 111, D10308, doi:10.1029/2005JD006454, 2006.

Strong, K., Barton, D., Bernath, P., Brown, S., Davies, J., Drummond, J.R., Fast, H., Farahani, E., Fogal, P., Goutail, F., Goutail, J. P., Hall, R., McConnell, J. C., McElroy, C. T., Melo, S. M. L., Midwinter, C., Murcray, F., Nowlan, C., Ogyu, A., Olson, J., Quine, B. M., Rochon, Y., Shepherd, T. G., Solheim, B. H., Sommerfeldt, D., Sullivan, R., Tingley, M., Toohey, M., Walker, K., Wardle, D. I., Wu, H., Wunch, D., Tarasick, D., and Ullberg, A.: The MANTRA 2002 balloon flight from Vanscoy, Canada, Proceeding of Envisat Validation Workshop, Italy, 9-13 December 2002, ESA SP-531, August 2003

Strong, K., Bailak, G., Barton, D., Bassford, M. R., Blatheiwick, R. D., Brown, S., Chartrand, D., Davies, J., Drummond, J. R., Fogal, P. F.,Forsberg, E., Hall, R., Jofre, A., Kaminski, J., Kosters, J., Laurin, C., McConnell, J. C., McElroy, C. T., McLinden, C. A., Melo, S. M. L., Menzies, K., Midwinter, C., Murcray, F. J., Nowlan, C., Olson, R. J., Quine, B. M., Rochon, Y., Savastiouk, V., Solheim, B., Sommerfeldt, D., Ullberg, A., Werchohlad, S., Wu, H., and Wunch, D.: MANTRA - a balloon mission to study the odd-nitrogen budget of the stratosphere., Atmos. Ocean, 43(4), 283-299, 2005.

Swartz, W. H., Yee, J. H., Vervack, R. J., Lloyd, S. A., and Newman, P. A.: Photochemical ozone loss in the Arctic as Determined by MSX/UVISI stellar Occultation Observations During the 1999/2000 Winter, J. Geophys. Res., 107(D20), 8296, doi:10.1029/2001JD000933, 2002.

Tsou, J. J., Connor, B. J., Parrish, A., Pierce, R. B., Boyd, I. S., Bodeker, G. E., Chu, W. P., Russell III, J. M., Swart, D. P. J., and McGee, T. J.: NDSC millimeter wave ozone observations at Lauder, New Zealand,1992-1998: Improved methodology, validation, and variation study, J. Geophys. Res., 105, 24263 $24281,2000$.

Urban, J., Baron, P., Lautié, N., Schneider, N., Dassas, K., Ricaud, P., and de La Noë, J.: Moliere (v5): A versatile forward- and inversion model for the millimeter and sub-millimeter wavelength range, J. Quant. Spectrosc. Radiat. Transfer, 83(3-4), 529-554, 2004a.

Urban, J., Lautié, N., Le Flochmoën, E., Ricaud, P., de La Noë, J., Dupuy, E., Drouin, A., El Amraoui, L., Eriksson, P., Frisk, 
U., Jimenez, C., Kyrölä, E., Llewellyn, E. J., Mégie, G., Murtagh, D., Nordh, L., and Olberg, M.: The Northern Hemisphere stratospheric vortex during the 2002-03 winter: Subsidence, chlorine activation and ozone loss observed by the Odin Sub-Millimeter Radiometer, Geophys. Res. Lett., 31, L07103, doi:10.1029/2003GL019089, 2004b.

Urban, J., Lautié, N., Jimenez, C., Le Flochmoën, E., Dupuy, E., Eriksson, P., Frisk, U., Murtagh, D., de la Noë, J., Olberg, M., and Ricaud, P.: Odin/SMR limb observations of stratospheric trace gases: Level 2 processing of $\mathrm{ClO}, \mathrm{N} 2 \mathrm{O}, \mathrm{HNO} 3$, and $\mathrm{O} 3$, J. Geophys. Res., 110, D14307, doi:10.1029/2004JD005741, 2005.

Von Savigny, C.: Retrieval of stratospheric ozone density profiles from OSIRIS scattered sunlight observations, Ph.D. Thesis, York University, Toronto, Canada, 2002.

Von Savigny, C., Haley, C. S., Sioris, C. E., McDade, I. C., Llewellyn, E. J., Degenstein, D., Evans, W. F. J., Gattinger, R. L., Griffoen, E., Lloyd, N., McConnell, J. C., McLinden, C. A., Murtagh, D. P., Solheim, B., and Strong, K.: Stratospheric Ozone Profiles Retrieved from Limb Scattered Sunlight Radiance Spectra Measured by the OSIRIS Instrument on the Odin Satellite, Geophys. Res. Lett., 30, 1755-1758, doi:10.1029/2002GL016401, 2003.
Wang, D. Y., Stiller, G. P., von Clarmann, T., Fischer, H., Glatthor, N., Grabowski, U., Höpfner, M., Kellmann, S., Kiefer, M., Linden, A., Mengistu Tsidu, G., Milz, M., Steck, T., Wohnsiedler, S., Lopez-Puertas, M., Funke, B. Gil-Lopez, S., Kaufmann, M., Koukouli, M. L., Murtagh, D., Lautié, N., Jimenez, C., Jones, A., Eriksson, P., Urban, J., de La Noë, J., Le Flochmoën, E., Dupuy, E., Ricaud, P., Olberg, M., Frisk, U., Russell III, J., and Remsberg, E.: Comparisons of MIPAS/ENVISAT ozone profiles with SMR/ODIN and HALOE/UARS observations, Adv. Space Res., 36(5), 927-931, 2005.

Warshaw, G. D., Desaulniers, D. L., and Degenstein, D. A.: Optical design and performance of the Odin UV/visible spectrograph and infrared imager instrument, Proc. 12th Annual AIAA/USU Conference on Small Satellites, 1998. 